\title{
PROCEEDINGS OF THE THIRTY-NINTH ANNUAL MEETING OF THE AMERICAN SOCIETY FOR CLINICAL INVESTIGATION HELD IN ATLANTIC CITY, N. J., MAY 5, 1947
}

The Antihemophilic Principle of Normal Plasma. BenJamin Alexander, Boston, Mass. (Introduced by $\mathbf{S}$. L. Gargill).

A method devised in our laboratories, for the quantitative measurement of the antihemophilic factor in normal plasma, has been applied to a study of some of its physiological and biochemical properties. The method is based upon the observation, now extended to include a total of 5 hemophiliacs, that the relationship between the logarithm of the amount of plasma added in vitro to hemophilic blood and the logarithm of its clotting time is linear.

The effects of normal plasma on hemophilic blood both in vivo and in vitro are constant and equivalent. The intravenous administration of 150 to $200 \mathrm{cc}$. of plasma 3 to 4 times weekly to 4 hemophiliacs has proved effective in the prevention of hemorrhage for periods of 6 to 16 months. Intramuscular plasma is much less effective in lowering the clotting time.

The antihemophilic potency of 46 non-hemophilic plasmas was uniform with a standard deviation of 0.3 in terms of an average of 1.0. The antihemophilic factor is largely retained by a Berkefeld filter but passes through a Seitz. The substance is no longer freely present following blood coagulation.

Frozen plasma remains fully potent for over six months but liquid refrigerated plasma $\left(5^{\circ} \mathrm{C}\right.$.) loses half of its activity in 5 weeks, 90 per cent in $21 / 2$ months. At $37^{\circ} \mathrm{C}$. one half is lost in 10 hours, 85 per cent in 24 hours. The rate of deterioration is uninfluenced by platelets or by the admixture of hemophilic plasma, but is much more rapid in whole blood, or normal plasma-whole hemophilic blood mixtures incubated at $37^{\circ} \mathrm{C}$. In the hemophiliac 93 per cent of the antihemophilic factor of infused plasma disappears within 13 hours.

Mixtures of normal and hemophilic plasma have a greater antihemophilic potency in vitro than normal plasma alone whereas hemophilic plasma is inert. The enhanced potency is referable to the hemophilic platelets.

These observations are of value both in the clinical management of hemophilia and in further elucidation of the mechanism of blood coagulation.

\section{Mechanisms Underlying Pulmonary and Cardiac Compli- cations of Electrically Induced Convulsions in the Treatment of Psychosis. M. D. Altschule and (by invitation) K. J. Tillotson, Boston, Mass.}

Convulsions induced by electroshock are accompanied by maximal forced expiration. During the seizure salivation occurs, and roentgenograms suggest also that bronchial secretion is likewise increased at this time. Maximal inspiration at the end of the seizure causes the aspiration of this material and gives rise to atelectasis more commonly than is suspected. Infection may localize in an atelectatic area and result in abscess formation. Increase in intrathoracic pressure during seizures exerts a force on the outside of the coronary arteries which prevents an increase in difference between the internal and external pressures on the walls of these arteries; brittle coronary arteries are thereby protected. Also, the changes in intrapleural pressure retard passage of blood from the periphery into the heart; this change is reflected in an increase in peripheral venous pressure. As a consequence of diminished venous return the heart becomes smaller than normal and its work is decreased. After the end of the convulsion, the cardiac work is increased, judging by changes in circulation time. The rush of blood from the periphery into the right auricle and great veins after the convulsion gives rise to cardiac arrhythmias which are vagal in type.

The Mechanism of Control of Extravascular Fluid Formation by Normal Human Serum Albumin in Cirrhosis and Idiopathic Hypoproteinemia with Normal Renal Function. S. Howard Armstrong, JR., and (by invitation) SAM T. Gibson, Boston, Mass.

In three patients periods of baseline control have exceeded six months, during which observations on water, salt, and nitrogen balances, plasma volume, protein distribution in serum and extravascular fluids, and differential osmotic pressure measurements yielding the effective osmotic pressure of the serum as against the extravascular fluid have been made.

When the course during control period suggested that the disease process was static for purposes of the experiment, albumin administration was started.

Cessation of formation of extravascular fluid has been observed when the differential osmotic pressure attains the level of normal osmotic pressure for man. Fluid formation recurs when this pressure falls to original levels. The variables unrelated to osmotic pressure do not appear to have first-order significance. In the effect in these patients without significant protein loss in the urine, the amount of albumin required to maintain this differential pressure is far less than the initial amount required to attain it. From the amounts used, together with the nitrogen balances, rough estimates have been made of tissue protein depletion which must be met before blood proteins rise in these patients.

Whereas the albumin has appeared to eliminate the disability of being waterlogged in these selected patients, the studies are not sufficiently wide to permit any conclusions on the effect of therapy on the underlying course of the disease.

\section{Vascular Spiders and Palmar Erythema in Pregiancy* WILlIAM B. BEAN and (by invitation) MoRRIS W. Dexter and Robert C. Cogswell, Cincinnati, Ohio.}

An extension of studies on vascular spiders and palmar erythema which may complicate liver disease has been made to determine the incidence, progress and fate of

\footnotetext{
* Aided by a grant from the U. S. Public Health Service.
} 
these vascular changes during and after uncomplicated pregnancy. Observations on 274 colored and 178 white women have been made at each routine visit to the $\mathrm{Ob}$ stetric Prenatal Clinic; 70 colored and 26 white women have been observed shortly after delivery and 6 weeks later. Including the earliest definite lesions, vascular spiders have been found in 65 per cent of white women and 15 per cent of colored women. Palmar erythema was detected in 58 per cent and 32 per cent respectively; and both types of vascular changes existed simultaneously in 43 per cent and 10 per cent. Incomplete data on the time of appearance of lesions indicate that they may begin at any time during pregnancy. Since many patients made their first clinic visit late in pregnancy very few known lesions were seen before the fifth month. In more than two-thirds of the patients the acquired vascular spiders and palmar erythema had disappeared by the 3rd to 5th days following delivery, and a few more had vanished by the time of the 6-week follow-up visit. Studies of liver function and urinary excretion of steroid hormones are in progress.

Physiological Studies in Congenital Heart Disease* Richard J. Bing, Leroy D. Vandam, and Frank D. GraY, JR., Baltimore, Md. (Introduced by E. Cowles Andrus).

One hundred eighty patients with congenital heart disease of the cyanotic group were studied. Pulmonary capillary flow was measured using the indirect Fick principle. Formulae for the determination of the volume flow through the pulmonary artery, the systemic capillaries, and through the aorta were devised from results obtained by catheterization of the heart. Similarly, the amount of mixed venous blood perfusing the lung (effective pulmonary blood flow), the size and direction of the intracardiac shunt, and the volume of collateral circulation to the lung were measured.

The effect of a standard exercise test on circulatory and respiratory functions was studied.

In tetralogy of Fallot the intracardiac shunt was directed from right to left. Large collateral circulation to the lung was present in most cases.

The arterial oxygen saturation was found to be related to the percentage of total mixed venous blood perfusing the lung. The systolic pressure in the right ventricle was elevated, and peripheral resistance varied with the logarithm of the systemic flow.

The basal metabolic rate was below normal. During the exercise test the ratio of oxygen consumption per liters of ventilation and the arterial oxygen saturation declined.

The Blalock operation was followed by an increase in the pulmonary capillary flow, the effective pulmonary blood flow, and the arterial oxygen saturation.

In Eisenmenger's complex the pulmonary artery flow was normal. Both systolic and diastolic pressures in the pulmonary artery were elevated. During the exercise test the ratio of oxygen consumed per liters of ventilation increased, and the arterial oxygen saturation declined.

* This work was supported by a grant from the Commonwealth Fund.
The Effect of Ouabain on the Dynamics of the Circulation in Patients with Congestive Heart Failure. RICHard A. Bloomfield, Bernard Rapoport, J. Pervis Milnor, Walter K. Long and J. Gilmer Mebane (by invitation) and LAurence B. Ellis, Boston, Mass.

The effect of ouabain upon the circulation in congestive heart failure was studied in a series of patients by utilizing the intracardiac catheterization technique. Cardiac outputs, by the direct Fick method, were determined before and at 1 to 2 hours after administration of $1 / 2$ to $1 \mathrm{mg}$. of the drug through the catheter. Simultaneous recordings through Hamilton manometers were made at frequent intervals over the same period of time of the peripheral venous, femoral arterial, and right intraventricular pressures; in addition, where possible, registration of the pulmonary arterial pressure was also done. Changes in heart rate were for the most part of a small order and did not explain observed alterations in other measurements. In those patients with congestive heart failure in whom the administration of ouabain was followed by a significant rise in the cardiac output no consistent or significant pattern of peripheral venous pressure change was observed; in fact, in some of the patients with marked increases in cardiac output the venous pressure was unchanged. In most patients there was an early and at times sustained rise in the systemic blood pressure. The data obtained failed to substantiate the view that the primary effect of the cardiac glucoside was due to a peripheral action on the venous pressure. The significance of the changes observed in the cardiodynamic measurements, including peripheral and right intracardiac pressures, is discussed, and it is concluded that they are consistent with a transfer of blood from the pulmonary and venous pools to the systemic side of the circulation.

High Penicillin Plasma Concentration by the Use of Caronamide, a Compound That Inhibits Penicillin Excretion by the Renal Tubules. WILLIAM P. Boger (by invitation), Calvin F. KAY and (by invitation) SylvaN H. Eisman and Elmer E. Yeoman, Philadelphia, Pa.

The reversible and physiologic inhibition of penicillin excretion by the renal tubules following the oral administration of caronamide, 4'-carboxy-phenylmethanesulfonanilide, has recently been described. It has been shown that when penicillin is administered parenterally or orally, the resultant plasma concentrations can be enhanced from two to seven times by reasonable caronamide doses given orally.

This work was stimulated by the necessity of attaining high penicillin plasma concentrations for the treatment of a patient suffering from subacute bacterial endocarditis due to a streptococcus viridans highly resistant to both streptomycin and penicillin. Very high plasma concentrations of penicillin have been achieved (fourteen to forty units of penicillin per cubic centimeter), following the oral administration of caronamide every three hours and the intramuscular injection of 500,000 units of penicillin every three hours. Dose-response curves following the injection of penicillin have been compared in control and caronamide treatment periods in order that the enhancement effect of caronamide could be evaluated. The peni- 
cillin plasma concentrations have been correlated with the quantities of penicillin recovered in the urine, the plasma concentration of caronamide, the renal clearance of penicillin, and the glomerular filtration rate as determined by mannitol clearance.

\section{Estimated Hepatic Blood Flow and Bromsulfalein Ex- traction in Normal Man During the Pyrogenic Re- action. Stanley E. Bradley and (by invitation) Neal J. Conan, New York, N. Y.}

The present study was undertaken to determine whether hepatic circulatory adjustments and/or hepatic cellular dysfunction develop in man during the pyrogenic reaction. The cardiac output and the renal blood flow increase even when fever is prevented by antipyretic drugs, and, since renal hyperemia is not sufficient to account for the increment in cardiac output, it may be presumed that the hepatic circulation is also increased. Recently it has been found that bromsulfalein (BSP) retention occurs during fever. This phenomenon may be attributed to (1) hepatic ischemia with reduced delivery of BSP to the liver or (2) diminished ability of hepatic cells to remove the dye from blood perfusing the liver.

The hepatic blood flow (EHBF) was estimated as the bromsulfalein clearance and BSP extraction was determined directly using the technique of hepatic venous catheterization. Studies were made upon normal human subjects prior to, and following, intravenous administration of typhoid vaccine.

Within one to two hours after pyrogen was given EHBF increased significantly in nearly every case (300 per cent above the control level on one occasion). Despite hepatic hyperemia and the resulting increase in BSP loading the removal of BSP from the blood decreased by as much as $\mathbf{5 0}$ per cent. This effect was apparently attributable to a striking reduction in BSP extraction by the liver. Premedication with aminopyrine prevented fever but did not alter the responses.

On several occasions, the hepatic venous pressure was observed to rise as hepatic hyperemia developed.

Streptomycin and Tuberculous Tracheo-Bronchitis. A Bronchoscopic Study of Healing Lesions. Lyman A. Brewer III, EmIL Bogen and Robert L. Brereton, San Fernando, Calif. (Introduced by J. M. Hayman, Jr.).

Visible lesions are especially suitable for the early ovaluation of therapeutic effects in tuberculosis. Thirteen tuberculous patients with persistent, severe, tracheal or bronchial granulating or ulcerative lesions were selected from more than a hundred referred for this purpose. They were intensively treated with streptomycin, both intramuscularly and by aerosol, at the San Fernando Veterans Administration Hospital for periods ranging from one week to three months. Biweekly bronchoscopic examinations showed prompt disappearance of the lesions in every case. Only one instance of recurrence of an ulcer in the tracheo-bronchial mucosa has been seen since the treatment has been discontinued. Pulmonary cavities in these patients remained open, and temporary symptomatic improvement in other lesions in the lungs were not sustained. Special clinical and laboratory studies before, during and after the treatment period help clarify the phenomena observed. This study indicates that streptomycin is a valuable therapeutic agent in the treatment of the most severe types of active tuberculous tracheobronchitis.

\section{Streptomycin in the Treatment of Draining Tuberculous} Sinuses. Benjamin L. Brock, Oteen, N. C. (Introduced by Arthur M. Walker).

One of the most dramatic results in the treatment of tuberculosis in man has been obtained following the use of streptomycin in draining tuberculous sinuses.

Sixty draining sinuses, proved to be tuberculous either by culture or biopsy, originating for the most part in bone or cartilage in eleven negro patients and one white patient have been treated with streptomycin over a period of from 90 to 150 days.

A daily dose of $1.8 \mathrm{gm}$. of streptomycin, or $0.3 \mathrm{gm}$. every four hours was given intramuscularly.

Nine (15 per cent) of the 60 sinuses closed within one week to four weeks and nine (15 per cent) closed within six weeks to eight weeks after streptomycin was begun. It required between ten weeks and twelve weeks for thirty ( 50 per cent) of the sinuses to close and the remaining eleven (approximately 20 per cent) closed within thirteen to twenty weeks after streptomycin therapy was instituted. Only one sinus remains following surgical drainage but it is almost closed.

The longest time which has elapsed since closure of a sinus is seven months, one week after therapy was begun; the shortest time one month. The average time since closure of all the sinuses is 3.8 months.

Where necrotic bone, or cartilage, as for example in a rib, is removed and where small abscesses under the skin, or large psoas abscesses in the groin are widely drained in conjunction with streptomycin therapy, arrest of the process with closure of the sinus occurs within a relatively short time.

Certain reactions to streptomycin are described and several outstanding clinical signs of improvement are discussed. Photographic illustrations are available.

\section{Analysis of Peritoneal Washings for Protein, Non-Pro- tein Nitrogen and Phosphorus During Studies on Ni- trogen and Fluid Balance in Treatment of Acute Uremia by Peritoneal Lavage. Herbert R. Brown, JR., Jacob Holler and Helen E. Van Alstine, Roches- ter, N. Y. (Introduced by Samuel H. Bassett).}

A woman of 25 years who developed acute anuria during the course of glomerulonephritis was treated for 21 days by continuous peritoneal irrigation using the method of Fine. The procedure was terminated by death of the patient. During the interval of study it was possible to (a) keep a fairly complete nitrogen balance (b) get rid of severe edema (c) increase the plasma $\mathrm{CO}_{2}$ from 20 to 60 volumes per cent and (d) reduce the level of NPN in the blood.

A very considerable amount of protein $(731 \mathrm{gm}$.) was recovered from the peritoneal washings. The mechanism of this was thought to be the establishment of partial 
equilibrium between the perfusing solution and the patient's interstitial fluid. Increased capillary permeability, believed to occur in acute nephritis, may have been a contributing factor to protein transudation in the early phase of lavage.

The overall picture of the $\mathrm{N}$ balance (exclusive of three small stools and losses from the skin) may be tabulated as follows:

\section{Nitrogen Balance}

\section{Nitrogen Intake}

Whole Blood (Intravenously) Plasma (Intravenously)

Aminoids (orally)

Special formula (orally)

Total

$$
\begin{gathered}
63.3 \mathrm{gm} . \\
99.6 \mathrm{gm} . \\
76.5 \mathrm{gm} . \\
36.6 \mathrm{gm} . \\
\hline 276.0 \mathrm{gm} .
\end{gathered}
$$

$276.0 \mathrm{gm}$.

Nitrogen Output

Peritoneal Drainage
(a) NPN
$140.8 \mathrm{gm}$.
(b) Protein $\mathrm{N}$
$117.0 \mathrm{gm}$

Gastric Suction (Wangensteen) $92.5 \mathrm{gm}$. Urine

$4.4 \mathrm{gm}$.

Total

$354.7 \mathrm{gm}$.

$354.7 \mathrm{gm}$.

\section{Difference (Nitrogen loss)}

could be accounted for by the volume of the water in the $\mathrm{Na}$ compartments.

The urine concentrations of $\mathrm{Na}$ of the normal subjects were essentially the same as for the blood. That of the patient with congestive heart failure was uniformly lower but varied with the phase of the congestive heart failure and the $\mathrm{Na}$ in the diet. The "Na clearances" in the patients with congestive heart failure were lower than those in the normal subjects. The $\mathrm{Na}^{24}$ appeared in the urine of all subjects within 1.5 to 3.5 .minutes after injection.

The data show an impairment of sodium excretion in congestive heart failure due largely to renal dysfunction.

Miliary and Meningeal Tuberculosis Treated with Streptomycin. PaUL A. BunN, Washington, D. C. (Introduced by Thomas McPherson Brown).

From May 1946 until February 20, 1947, 60 cases of proved meningeal and miliary tuberculosis, or a combination of both, have been treated in 38 Veterans Administration hospitals. The number of cases in each group, the death and survival rates according to the time treated, and the number who are living after completion of an assigned course of streptomycin are shown in the figure.

\begin{tabular}{l|c|c|c|c|c|c}
\hline \hline Disease & $\begin{array}{c}\text { Num- } \\
\text { ber } \\
\text { of } \\
\text { cases }\end{array}$ & $\begin{array}{c}\text { Dead, 27, } \\
\text { following } \\
\text { treatment } \\
\text { days }\end{array}$ & $\begin{array}{c}\text { Living, 33, } \\
\text { following } \\
\text { treatment } \\
\text { days }\end{array}$ & $\begin{array}{c}\text { Treat- } \\
\text { ment } \\
\text { "com- } \\
\text { pleted" }\end{array}$ \\
\cline { 2 - 4 } & $0-7$ & $15-120$ & $10-30$ & $30-125$ & \\
$\begin{array}{l}\text { Meningitis } \\
\text { Miliary }\end{array}$ & 24 & 8 & 5 & 8 & 3 & 0 \\
$\begin{array}{l}\text { Meningitis } \\
\text { and miliary }\end{array}$ & 17 & 0 & 2 & 2 & 10 & 3 \\
\hline Totals & 60 & 13 & 7 & 0 & 4 & 3 \\
\hline
\end{tabular}

Only those cases falling into the classification of acute disseminated miliary tuberculosis and those with classical signs of meningitis are included. Without specific antibacterial therapy, the expected mortality of each group would approximate 100 per cent.

Of the 6 cases who have completed treatment to date, 4 are to all intents and purposes normal-both clinically and psychologically. The fifth continues to have active pulmonary tuberculosis and the sixth has developed irreparable brain damage.

The clinical improvement, the laboratory findings and the roentgenographic changes in all cases during the period of therapy have been recorded and are extremely impressive in most instances. Complete $x$-ray clearing of all miliary lesions in the lungs has been demonstrated on occasions.

Many evidences of toxicity to streptomycin have been recorded. Among these are three cases who developed complete deafness and one in whom there was bone marrow depression.

The dosage of streptomycin has varied from $1.2 \mathrm{gm}$. to $4 \mathrm{gm}$. daily given in divided doses. The duration of treatment has been variable. The material has been continuously administered for as long as $\mathbf{1 6 0}$ days, but in most, lected from arteries. The differences in blood $\mathrm{Na}$ levels between the normal and congestive heart failure subjects 
if the patient survives, therapy was stopped at the end of 120.

The Effect of Age on Phosphate Fractions in the Heart of the Rat. Gus G. CASTEN,* and M. F. MASON, Dallas, Texas. (Introduced by Tinsley R. Harrison).

A comparison has been made between young adult male rats (about 3 months old) and elderly male rats (about two years old) in regard to the content of the heart in various phosphate fractions. No significant difference was found in regard to the inorganic phosphate or the adenosine triphosphate. Striking differences were observed in the creatin phosphate fraction which was about twice as great in the young as in the older rats. Since the creatin phosphate constitutes the reserve from which adenosine triphosphate, the direct source of energy, may be derived under conditions of stress, the findings are in general agreement with the conception that aging is associated with a decline in the reserve power of the heart. The reasons why heart and skeletal muscle (as judged from the work of others) differ in respect to the effect of age on creatin phosphate content are not clear.

Further studies dealing with the effect of experimental heart failure on the various phosphate fractions are in progress.

Sulfathiazole as a Substitute for Inulin in Determining the Glomerular Filtration Rate. DoN W. ChapMaN, and

S. A. Peoples, Houston, Texas, (Introduced by James A. Greene).

An accurate method for measurement of glomerular filtration has been developed, by which a larger number of patients can be studied more quickly, and is simple enough for routine clinical studies.

Sulfathiazole was given orally and its clearance compared with that of inulin. Urine specimens were obtained by catheterization at twenty or thirty minute intervals, and blood samples were drawn at the mid-points of each interval. The urine and plasma were analyzed for sulfathiazole by the method of Bratton and Marshall and the plasma albumin by the method of Greenberg. The free plasma sulfathiazole was calculated from the total plasma sulfathiazole, from the concentration of plasma albumin by means of the adsorption formula

$\frac{\text { Free Sulfa }}{\text { Total Sulfa }}=\frac{1}{\mathrm{~K} \times \text { Albumin Conc. }+1}$, where $\mathrm{K}=0.45$.

The $\mathrm{K}$ value was obtained from simultaneous clearance studies of inulin and sulfathiazole in humans.

Maximum deviation of simultaneous clearance of inulin and sulfathiazole in 25 patients was 11 per cent, and an average deviation of 6 per cent. The data show that sulfathiazole clearance is as reliable as inulin clearance in patients with normal and with reduced renal function.

\footnotetext{
* Done during the tenure of a Life Insurance Medical Research Student Fellowship.
}

Study of Standard Metabolism in Relation to Degenerative Processes in the Aged. Margaret Chiefri, St. Louis, Mo. (Introduced by William B. Kountz).

A detailed study was made on about 500 patients over 40 years of age. Some of these were followed over an extensive period, up to eight years, and were studied repeatedly.

The individuals were either residents in a chronic disease hospital or were visitors to a private clinic. The result of the studies showed the individuals to form a series varying from those with earliest signs of degeneration (which on repeated study were found to be progressive) to those with advanced degenerative changes.

Many interesting variations were noted in a study of the different tests. Changes in the basal metabolism seemed to be the most significant and the results will be considered.

In those individuals with early degenerative changes the metabolism was usually low, varying from -10 to -28 and averaging about -15 .

The individuals with advanced degenerative changes and with residuals of diseases such as coronary artery disease, intracranial lesions etc. frequently show an elevated basal metabolic rate not only as compared with the first group but even compared with the normal standard. Repeated studies in these individuals showed a rising metabolic rate.

Results of attempts to modify the metabolism by feeding experiments and administration of hormones will also be discussed.

Rapid Quantitative Assay of Proteolytic Enzyme Inhibitors in a Fibrinogenolytic System and the Significance of the Plasma Inhibitor in Experimental Peritonitis in the Dog. Donald G. C. Clark, New Haven, Conn. (Introduced by John S. Lockwood).

Preliminary investigation of experimental peritonitis in the dog has suggested that the level of proteolysin inhibitor in the plasma is a factor in the ability of the animals to survive the disease. In this work 29 pairs of dogs were subjected to peritonitis; one of each pair was prepared by the daily injection of protease for 5 days prior to operation in an attempt to raise the level of proteolysin inhibitor, as suggested by the work of Grob, while the other of each pair was used as a control. The difference in mortality was significant, 5 dogs dying from the prepared group (17.2 per cent) and 20 from the control series (68.9 per cent).

Since the difference in mortality appeared to be a result, at least in part, of the much more marked production of fibrin around the abscess in the treated animals, as shown at autopsy, it was felt that the effect of the proteolysin-inhibitor system on the stability of fibrinogen might be the significant factor. This, together with the fact that fibrinogen is highly sensitive to the action of proteolysins such as trypsin, led to the development of an assay method employing fibrinogen as the substrate.

In the method serial dilutions of serum from the animal are allowed to react with a known amount of trypsin for a fixed period to allow the proteolysin and proteolysin inhibitor to react together. Then a standard quantity of 
lysin-free fibrinogen is added. The formation of a clot upon addition of thrombin, after a standard period of incubation at $37 \mathrm{C}$., indicates that the trypsin has been inhibited, and affords a clear-cut end-point; no clot forms if the quantity of inhibitor has been insufficient to block the added trypsin. Temperature, $\mathrm{pH}$, and timing of the various phases of the reaction must be carefully controlled.

The normal dog shows a level of inhibitor equivalent to from 300 gamma to 450 gamma crystalline soy bean trypsin inhibitor (Kunitz) per ml. serum. Following injections of protease, however, the inhibitor level at first falls and then returns to the initial level with increasing speed on each subsequent injection. The length of the recovery period decreases from about 9 hours after the initial injection to about 1 hour after the fifth injection. Also, in most animals the titre increases gradually with each successive injection to about double the original value. In about one-quarter of the animals studied this absolute increase did not develop.

It seems probable that a stable equilibrium between plasma protease and its inhibitor is a factor in the effective deposition of fibrin within the peritoneal cavity, and in recovery from peritonitis.

The Effect of Castration and Di-ethyl Stilboestrol in a Patient with Myelophthisic Anemia Secondary to Carcinoma of the Prostate. ROBERT R. CoMmons (by invitation) and MaUrice B. Strauss, Framingham, Mass.

Severe myelophthisic anemia may be the first and outstanding manifestation of carcinoma of the prostate with widespread skeletal metastases. Three such cases have been observed, in none of which were prostatic symptoms presenting.

The first two of these patients, observed prior to the introduction of castration and female sex hormone administration in the treatment of prostatic cancer, died within a few months of diagnosis, with their anemia controlled only by blood transfusion. The third patient was castrated after a three weeks intensive course of liver and iron therapy had been accompanied by a further decline in blood values. Five mg. of di-ethyl stilboestrol was then administered by mouth daily. No other treatment was employed. Bone pain, ascribable to metastatic skeletal involvement, disappeared within four weeks. No reticulocyte increase occurred but a definite slow rise in red blood cells and hemoglobin occurred from an original level of 1,990,000 erythrocytes per cu. $\mathrm{mm}$. and $5.1 \mathrm{gm}$. of hemoglobin per $100 \mathrm{cc}$. to values of $3,530,000$ and 11.0 gm. two months after the institution of treatment. $\mathrm{Nu}$ cleated red blood cells, which had been present in the proportion of 1 to 100 leukocytes, disappeared from the peripheral blood.

Since neither castration nor the administration of diethyl stilboestrol has been reported to produce increases in red blood cells and/or hemoglobin in man or animals, it appears probable that one or both of these procedures so affected the cancerous metastases in the bone marrow of this patient that more normal hematopoiesis took place. It is of interest that in spite of the striking change in the blood values, $x$-ray examination failed to show any change in the extent or severity of the bone changes.
The Effect of the Upright Posture upon Hepatic Blood Flow in Normal and Hypertensive Human Subjects. James W. Culbertson (by invitation), Robert W. Wilkins, Franz J. Ingelfinger and Stanley E. BradLey, Boston, Mass.

Hepatic blood flow was estimated in seven normal and twelve hypertensive subjects by means of the bromsulphalein clearance technique with hepatic venous catheterization. Arterial pressure and pulse rate were recorded at two-to five-minute intervals throughout the two-hour test.

Each subject was placed supine on a tilt-table and studied first in a horizontal position, then after being tilted upright $\left(75^{\circ}\right)$, and then in the horizontal position again. Serial pairs of peripheral and hepatic venous blood samples were drawn at five- to ten-minute intervals, three or more for each tilt-table position unless syncope intervened during the upright study.

Values for estimated hepatic blood flow in both groups of subjects before tilting fell within normal range and averaged $1400 \mathrm{ml}$. per minute per $1.73 \mathrm{sq} . \mathrm{m}$. of body surface. After the tilt to upright the values decreased sharply by 15 to 60 per cent, with an average approaching 40 per cent and no significant difference observed between normal and hypertensive individuals. Following return of the table to the horizontal position hepatic blood flow increased, rising toward or above the pre-tilt control rate.

These results are interpreted as indicating that splanchnic vasoconstriction occurs in the upright position, since the decreases in blood flow could not be accounted for by significant changes in blood pressure.

An Objective Method for Evaluating the Anti-Asthmatic Effect of Several Sympathomimetic Amines in Man. JoHN J. CurRy, Boston, Mass. (Introduced by Francis C. Lowell).

The effectiveness of various anti-asthmatic compounds usually has been determined by analyzing the subjective response of large groups of patients. Measurements of increase in vital capacity following the administration of various drugs during the acute asthmatic attack have also been made. Both types of study, however, are subject to unaccountable variations and are difficult to evaluate.

It has been shown that a quantitative decrease in the vital capacity may be produced in certain asthmatic subjects, during periods when they are relatively asymptomatic, by the parenteral administration of histamine and acetyl-beta-methyl choline. Various sympathomimetic amines, anti-histamine compounds and anti-cholinergic agents protect these subjects against the reduction in vital capacity in a characteristic fashion. These findings suggested that the degree of such protection, afforded by various anti-asthmatic drugs, might furnish an objective method for assaying their effectiveness in the treatment of asthma.

In the present study, using this method, several sympathomimetic amines were compared with ephedrine sulfate. Only one compound, beta-o-methoxyphenyl isopropyl methylamine, compared favorably with ephedrine. This was of interest since the compound has little pressor 
or C.N.S. stimulating effect. Clinical studies in a group of asthmatic patients supported the results of the assay and the validity of the method.

Relative Importance of Tonicity and of Extracellular Volume in Salt Depletion Shock. T. S. DANowskI, A. W. Winkler and J. R. Elkinton, New Haven, Conn.

Studies have been conducted to determine whether salt depletion shock is mediated primarily through hypotonicity or through a decrease in the volume of the extracellular fluid. Previously reported experiments indicated that in the salt depleted animal restoration of extracellular and plasma volume without replacement of salt failed to improve the circulation. The results suggested that the hypotonicity and associated cellular overhydration had a deleterious effect per se.

In the present experiments hypotonicity of body fluids in the presence of a normal salt content was produced in 3 nephrectomized dogs by the infusion of glucose solution. Changes in the electrolyte and water content of plasma, extracellular fluid, and of cells were calculated and alterations in the hemodynamics (cardiac output, circulation velocity, and mean arterial pressure) were measured.

Those animals in whom body fluids had been diluted resembled those depleted of salt in that hypotonicity was present. They differed, however, in that the extracellular volume was expanded rather than contracted, and despite the hypotonicity, the circulatory efficiency was unimpaired or improved.

In 2 other animals salt depletion shock was produced by the Darrow-Yannett technique. Subsequently a diuresis was induced by intravenous urea solution and the hypotonicity which resulted from the salt depletion was corrected. The extracellular fluid volume declined further, however, and despite the restoration of isotonicity the cardiovascular function did not improve.

It is concluded that within certain limits both tonicity and extracellular volume, i.e., the amount of salt present, must condition the development of salt depletion shock.

Streptomycin in the Treatment of Pulmonary Tuberculosis. Nicholas D. D'Esopo, Stanton T. Allison, Benjamin L. Brock, W. A. Cassidy, and Arnold Shamaskin, Baltimore, Md. (Introduced by James Bordley III).

120 cases of pulmonary tuberculosis were treated for 4 months with 1.8 grams of streptomycin intramuscularly daily. Patients were selected on the basis of stationary or progressive lesions with an important exudative component during a pre-treatment observation period of at least 3 months. The majority were far-advanced.

Mean blood levels of 18 micrograms and 10 micrograms of streptomycin per cc. after 1 and 4 hours respectively were obtained.

Decline in fever, increased appetite, gain in weight, and a marked decrease in sputum amount were consistently observed.

Resolution of lesions, to a greater or lesser extent, was noted in 77 per cent. In 18 per cent the degree of resolution was striking. No new lesions developed under treat- ment, nor did established lesions progress. The most favorable effect was seen in cases of predominantly exudative disease. Cavities tended to become smaller, but unequivocal closure was infrequently observed.

Sputum or gastric cultures became negative in 30 per cent of patients.

Toxicity was manifested by subjective vertigo in 90 per cent, an abnormal urinary sediment in $\mathbf{5 0}$ per cent, and a transient rash in 10 per cent. Treatment was discontinued in 3 cases.

After 6 weeks the tubercle bacilli of 27 per cent showed in vitro resistance to concentrations of streptomycin obtained at this dosage; and at 4 months 53 per cent developed resistance. In the great majority resistance developed abruptly.

Streptomycin is most useful in controlling symptoms and the recent exudative lesion. It is suppressive rather than definitive therapy. The development of resistant organisms is a disadvantage since there is an inverse correlation between resistance and therapeutic response.

Cardiac Oxygen Metabolism. J. E. Eckenhoff, J. H. Hafkenschiel and M. Harmel, Philadelphia, $\mathbf{P a}$. (Introduced by Francis C. Wood).

In spontaneously breathing dogs lightly anesthetized with nembutal, coronary blood flow was measured by the bubble flowmeter technic and cardiac metabolism determined by a method previously described. In an attempt to elucidate the inter-relationships of coronary flow, arterial pressure, cardiac output, cardiac efficiency and cardiac oxygen metabolism, three groups of experiments were performed in which (1) arterial pressure, (2) cardiac output or (3) arterial oxygen content was primarily altered. In (1) and (2) coronary flow consistently followed cardiac oxygen consumption and in (3) coronary flow was found to increase as needed to meet cardiac oxygen requirements. The data indicate that the coronary vessels, like the cerebrals, possess an effective intrinsic control in relation to the metabolic requirements of the tissue supplied. Cardiac efficiency tended to vary directly with cardiac output and inversely with arterial blood pressure. Since coronary venous blood under the conditions of these experiments normally contained only 4 to 6 vol. per cent oxygen, there is obviously little room for removing appreciably larger amounts of oxygen. Agents intended to accomplish this are therefore open to question. The heart was found to be safeguarded from dangerous anoxia by three mechanisms: (1) decreased tonus in the coronary vessels, (2) diversion of a relatively larger fraction of the cardiac output to the coronary circulation, (3) decreased cardiac work with a resultant decrease in oxygen demand.

The Administration, Utilization and Excretion of a Mixture of Amino Acids in Man. R. D. Eck HARDT and T. L. MURPhy (by invitation), and C. S. DAvidson, Boston, Mass.

The 10 per cent solution of the ten "essential" amino acids used in these studies was prepared by complete acid hydrolysis of casein, was rendered free of aspartic and glutamic acids, and was fortified with dl-tryptophane, dl- 
methionine and glycine. In over 150 injections reactions were rare, and none of a pyrogenic nature was observed. Injections of $500 \mathrm{cc}$. (50 gm. amino acids) in 10-15 minutes rarely induced vomiting, although transient nausea occurred in approximately one-fourth of these cases. At a slower rate (one hour), even nausea was rare. Thrombosis of the infusion vein did not occur.

The blood amino acid level returned to within normal limits by four hours after the infusion, although it was often slightly above the pre-injection level. During this time, the maximum loss of the injected amino acids occurred (average 8 per cent). Urinary amino nitrogen excretion did not correlate with the rate of infusion, but was roughly proportional to the amount given and to the total 24-hour urine nitrogen.

Comparison was made between the percentage composition of the essential amino acids administered and excreted (microbiological assay). Lysine, methionine, phenylalanine and valine were excreted in approximately the same percentages as administered; histidine, threonine and tryptophane, in two to three times greater percentages; and arginine, leucine and isoleucine proportionately less.

The Restoration of Thermal Balance During Acclimatization to Work in a Hot Dry Environment. Ludwig W. Eichna, (by invitation) Charles R. Park, Norton A. Nelson, Edward D. Palmes, Steven M. Horvath and Walter B. Shelley and William B. Bean, Fort Knox, Ky.

When man first works in a hot environment his body temperature rises to abnormally high levels and disability often results. When acclimatized to the heat he performs the same work easily and with a lower, or normal, temperature. The methods of partitional calorimetry were used to determine the mechanisms responsible for this reduced heat retention.

Thermal balances were determined in 3 nude men as they acclimatized to work in a hot, dry (desert type) environment.* With acclimatization the bodily heat content fell; with deep tissues heat content reaching normal values but that in the peripheral tissues (skin) remaining above normal. Approximately 90 per cent of the total decrease in heat retention with acclimatization was due to increased evaporative cooling (increased secretion and evaporation of sweat); the remaining small decrease (10 per cent) resulted from a slight fall in metabolic heat production. Because of the increased evaporative cooling the skin temperature fell with acclimatization. This led to increased heat gains from the environment by convection and radiation as acclimatization developed. These increased external heat gains amounted to approximately 50 per cent of the increase in evaporative cooling and to that extent decreased the efficiency of the increased evaporative cooling in lowering the body temperature. However, the lower skin temperature promoted heat loss from deep to peripheral tissue by conduction and increased the cooling gradient for the blood brought to the skin. This

\footnotetext{
* Dry bulb temperature $102^{\circ} \mathrm{F}$., wet bulb temperature $80^{\circ} \mathrm{F}$.
}

permitted a reduced peripheral blood flow to the skin and thereby a more stable general circulation.

The Mechanism of Blood Destruction in Congenital Hemolytic Jaundice. Charles P. Emerson, JR., and Shu Chu Shen (by invitation), Thomas Hale Ham and William B. Castle, Boston, Mass.

Twenty-nine patients with congenital hemolytic jaundice were studied with particular reference to the nature of the red cell abnormality and the role of the spleen in this hemolytic syndrome. When subjected to sterile incubation in vitro, their red cells exhibited abnormally prompt increase in osmotic and mechanical fragilities. In certain individuals with minimal signs of hemolytic disease, who were members of the affected families, this increased mechanical fragility and susceptibility to incubation were the only evidences of red cell abnormality.

Eleven patients with congenital hemolytic jaundice were subjected to splenectomy. Red cells derived from the peripheral blood and from the splenic pulp were compared with respect to their osmotic and mechanical fragilities, and response to incubation. Similar studies were carried out on five patients subjected to splenectomy for conditions other than congenital hemolytic jaundice. Their red cells behaved like normal red cells. However, in all the cases of congenital hemolytic jaundice, the splenic pulp contained a high proportion of red cells that were markedly susceptible to hemolysis in hypotonic solutions and to mechanical trauma when compared to those in the peripheral blood. Post-splenectomy studies of the peripheral blood indicated a rapid disappearance of that portion of the heterogenous red cell population previously exhibiting the most marked increase in osmotic fragility and a return of the mechanical fragility of the blood nearly to normal.

Five patients were given several days before splenectomy massive transfusions of compatible blood possessing immunologic properties which distinguished it from the blood of the recipient. Employing selective agglutination technics it was ascertained that, in contrast to the patient's red cells, the osmotic fragility of these donor cells, including those separated from the splenic pulp, had remained unaltered. Finally, the ratio of patient's cells to donor's cells was found to be distinctly greater in the splenic pulp than in the peripheral blood, suggesting that selective retention of the patient's red cells had occurred. These data indicate that the hemolytic activity of the spleen, in congenital hemolytic jaundice, may derive solely from the fact that this organ serves as a locus of "erythrostasis," a process which in vitro demonstrably results in the rapid deterioration of the inherently defective red cells characteristic of the disorder.

The Effect of Diabetes and Insulin on Glucose Tm. SAUL J. FARBER and EUGENE Y. BERGER (by invitation), and David P. EArLe, JR., New York, N. Y.

A high renal threshold for glucose in diabetics has generally been attributed to a low glomerular filtration rate in the presence of a normal glucose reabsorptive capacity. Glucose $\mathrm{Tm}$, or maximum amount of glucose that can be reabsorbed per unit of time, is quite constant 
for an individual under standard conditions. Smith et al. found the average glucose $\mathrm{Tm}$ of normal women to be 303 mgm. per minute $(\sigma=55.3)$. Glucose Tm's determined in normal subjects in this laboratory have fallen within this range. Observations on a limited number. of middle aged female diabetic patients have shown an average glucose $\mathrm{Tm}$ of $433 \mathrm{mgm}$. per minute (Range = 401 to 460 ). The glomerular filtration rates of these patients were normal. The average ratio of filtration rate to glucose $\mathrm{Tm}$ was 0.270 as compared to the normal value of $0.395(\sigma=0.0617)$.

The continuous intravenous administration of small amounts of insulin to both normal and diabetic subjects resulted in a decrease in glucose $\mathrm{Tm}$ in all but one experiment. The average glucose $\mathrm{Tm}$ during insulin administration was 10 per cent under control values. Single injections of insulin resulted in transient decreases in glucose $\mathrm{Tm}$ of similar magnitude.

Studies on the Rate of Excretion of Water and Electrolyte by Young Infants. Gladys J. Fashena, Dallas, Texas.

Normal infants in the first six months of life, when given isotonic sodium chloride solution parenterally at the rate of 1 per cent of body weight per hour for five hours, excrete the excess loads of water, sodium, and chloride more slowly than adults. In twenty-four hours the average sodium excretion is 75 per cent of the load and the average chloride excretion 91 per cent of the load. The velocity quotients for sodium range between 0.03 and 0.06 , for chloride between 0.04 and 0.07 and for water between 0.02 and 0.1 . Two infants, recently recovered from dehydration and acidosis, show further impairment of their ability to excrete electrolyte. In these the velocity quotients of sodium and chloride were in the neighborhood of 0.01 and 0.02 respectively and both subjects became slightly edematous during the experiment. It is not known how frequently this type of response follows an episode of dehydration and acidosis and further studies on this point are in progress.

Methemoglobin Reconversion in the Erythrocyte. CLEMent A. Finch, Howard A. Eder, and Ralph W. McKee, Boston, Mass. (Introduced by George W. Thorn).

Hemoglobin in solution is spontaneously converted to methemoglobin. In the normal erythrocyte this is prevented by a system deriving its energy from carbohydrate metabolism. Studies of a patient with congenital methemoglobinemia have shown an intrinsic defect of the erythrocyte with complete failure of the normal reconversion mechanism. In the absence of cell reconversion, reducing substances appear to regulate the hemoglobinmethemoglobin equilibrium. The role of reducing substances was studied in this patient. It was also observed that methylene blue was able to activate in this patient the cell reconversion mechanism and the immediate and long term effects of methylene blue were studied. The effectiveness of ascorbic acid and methylene blue therapy has been evaluated in different etiological types of methemoglobinemia.
The Effectiveness in Experimental Syphilis of Penicillin in Peanut Oil-Beeswax Given in Sixteen Daily Injections.* William L. Fleming, Boston, Mass.

Seventy male rabbits inoculated intratesticularly with the Nichols strain of $T$. pallidum were proven to be syphilitic by demonstration of typical spirochaetes from testicular chancres. Eight weeks after inoculation they were treated with sixteen daily intramuscular injections of calcium penicillin suspended in peanut oil containing 4.8 per cent of beeswax by weight volume. Ten rabbits were treated at each of seven total dosage levels : 250,500 , $1,000,2,000,4,000,8,000$, and 16,000 units per kilogram. The concentration of penicillin had to be varied in order to administer the different dosages and was of necessity lower than that of the Romansky Formula. Proof of cure or treatment failure was determined by the darkfield examination of chancres or lesions suggestive of infectious relapses, and by lymph node transfers six months after treatment.

Results indicate that the C.D./50 (minimal dose necessary to cure 50 per cent of rabbits) was between 1,000 and 2,000 units per kilogram. This indicates effectiveness in the same order of magnitude as samples of a crude commercial penicillin and of crystalline penicillin G previously assayed after administration in intramuscular injections of aqueous solution every three to four hours for ninety-six hours.

Studies on the Relation of the Serum Albumin to the Formation of Bone Matrix. ANNE P. Forbes, Boston, Mass. (Introduced by Fuller Albright).

Osteoporosis is defined as that form of demineralized bone where the defect is in laying down the bone matrix. It has certain clinical characteristics which make its differentiation from other forms of demineralized bone certain. A case is presented with all the characteristic criteria of this disease in which the usual causes (postmenopausal state, disuse, Cushing's Syndrome, malnutrition, et cetera) were not present. The studies include metabolic balances of calcium, phosphorus and nitrogen in relation to the levels of the serum proteins. Various therapeutic regimens were tried. These included therapeutic abortion, plasma by vein, serum albumin by mouth and by vein, high and low protein diets, large doses of Stilbestrol, and Vitamin A. The evidence suggests that bone matrix formation is influenced by the serum albumin level.

Chemical and Electrophoretic Analyses of the Tissue Proteins in Shock from Tourniquet Injury or Burns. Charles L. Fox, Jr., and DaN H. Moore, New York, N. Y. (Introduced by A. R. Dochez).

Experiments were performed to test whether plasma proteins accumulate in tissues traumatized by tourniquetting or burning. Single hind legs of mice were injured by the application and release of tight tourniquets or scalding. When swelling was greatest and shock profound, both hind legs were amputated at the groin and the entire leg analyzed for water and total nitrogen.

\footnotetext{
* Done under an U.S.P.H.S. Research Grant.
} 
For electrophoretic analysis, similar legs were extracted in chilled buffer.

Injured legs did not contain more protein than contralateral, uninjured legs. If the fluid gained by the injured legs were chiefly plasma, approximately 10 to 20 per cent ( 20 to $50 \mathrm{mg}$.) more protein might be expected.

Electrophoretic analyses of the injured leg fluid disclosed no component with the mobility of albumin. Instead a faster, new component appeared; this was resolved from plasma albumin in artificial mixtures. In the ultracentrifuge, its sedimentation constant was greater than albumin.

These chemical, electrophoretic, and ultracentrifugal analyses dispute the view that plasma proteins accumulate in tissues injured by tourniquetting or scalding.

The Ventricular Gradient in Fever. A. S. FREEDBERG and M. J. McManus, Boston, Mass. (Introduced by H. L. Blumgart).

Published studies of the electrocardiographic changes during infections stress the occurrence of $\mathrm{ST}$ and $\mathrm{T}$ wave abnormalities. In these reports, however, it is often impossible to distinguish the effects of fever per se from those of myocardial changes due to many other factors commonly present in infectious disease. The method of Wilson et al. for determining ventricular gradients was therefore applied to 3 standard limb lead electrocardiograms obtained during fever induced by intravenous injection of typhoid vaccine in 9 human subjects.

The ST segment depression and $\mathrm{T}$ wave inversion occurring in typhoid vaccine fever are (a) primary and (b) secondary. The latter may be related to increased rate and/or a change in heart position. The former resemble the changes observed after digitalis administration and indicate a physiologic alteration in the myocardium related to the induced fever. In two patients pronounced shift in ventricular gradient direction occurred in the chill and flush phase. This indicates a local alteration in duration of the excited state, similar to that observed in local myocardial ischemia. These alterations in ventricular gradient consequent to fever must be considered in the interpretation of $\mathrm{T}$ wave and ST segment changes in febrile states, both endogenous and physically induced.

\section{Assay of Urinary Estrogens by Ultraviolet Absorption Spectrophotometry. HARRY B. FRIEDGOod and (by in- vitation), Josephine B. Garst, Pasadena, Calif.}

Previous studies have demonstrated that ultraviolet absorption spectrophotometry can be applied to the quantitative determination of pooled or single samples of crystalline estrone, estradiol and estriol by virtue of the type of absorption curves and concentration-extinction relations which these hormones exhibit under controlled experimental conditions. Further investigations with this quantitative technic have disclosed that current chemical methods do not effect a clean-cut separation of the androgens from the estrogens or of estriol from the estrone-estradiol fraction. The significant losses of estrogens involved in these manipulations have been difficult, if not impossible, to estimate accurately because of the relative lack of sensitivity of the colorimetric and bioassay methods of quantitation as compared with that of ultraviolet absorption spectrophotometry. On the basis of these findings, a new method has been developed - for the accurate separation and assay of the three estrogens in aqueous-alcoholic solution. A study has been made of the factors involved in the application of ultraviolet absorption spectrophotometry to the extraction and separation of the estrogens from urine-with particular reference to the removal of the background material which interferes with the quantitative reading of the estrogen curves.

The Relationship between Calcium and Digitalis Glycoside in Respect to Their Action upon the Embryonic Duck Heart. MEYer FrIEdMAN and (by invitation) Rene Bine, Jr., San Francisco, Calif.

The embryonic duck heart was found to be similar to the mammalian heart in its response to excess digitalis glycoside (Lanatoside C.), in that it reacted to the presence of the latter drug by (1) acceleration of rate, (2) increased force of contraction and (3) appearance of arrhythmia. This particular property of the embryonic heart, together with its ability to beat weakly but persistently in the complete absence of calcium or in an excess of the latter, allowed an unique opportunity for the study of the relationship between calcium and digitalis glycoside in their effects upon the heart. The absence of an extrinsic nerve supply to the embryonic heart (at stage of development, used) allowed such a study to be strictly of the cardiac musculature, alone.

The completed studies indicated that the action of calcium alone was completely dissimilar to that of digitalis, irrespective of the concentration of the former. Furthermore, it was found that the calcium ion and the digitalis glycoside employed, bore no synergic relationship to each other in respect to their individual or combined effects upon the heart. Finally, it was discovered that the characteristic action of digitalis was not inhibited by the complete absence of the calcium ion.

Arterial Pressure Pulse Waves in a Patient with Coarctation of the Aorta. Morton Galdston (by invitation) and J. Murray Steele, New York, N. Y.

Arterial pressure was recorded with Hamilton manometers simultaneously in radial and femoral arteries of a middle aged patient suffering from coarctation of the aorta. The usual pressure differences were observed (radial 215-225/100 mm. Hg; femoral 150/100 mm. Hg).

Of greater interest than these differences was the remarkable similarity between pulse waves from the left radial and left subscapular collateral artery, in spite of entirely different physical arrangements of the arterial tree distal to the points from which these pressure waves were recorded, as observed at autopsy. The radial arteries were of normal origin and distribution. The enlarged, tortuous subscapular arteries joined enlarged 5th and 6th intercostal arteries which entered the aorta below the coarctation. The main collateral vessels emptied into enlarged 3rd and 4th intercostal arteries just 
below the coarctation, the lumen of which measured 0.5 $\mathrm{cm}$.

Since variations in form of pressure curves in the arterial tree are considered to be influenced partly by waves reflected from distal arterioles and to a lesser degree by standing arterial waves, the similarity of the radial and collateral artery pulse waves is difficult to explain. A similar form of pulse wave has been demonstrated in another patient with coarctation of the aorta and in patients with hypertension when the artery was partially constricted above the point of recording.

Studies of the Relationship of Niacin and Tryptophane in Human Metabolism. Grace A. Goldsmith and (by invitation) HERBerT P. SARETT, New Orleans, La.

Metabolic balance studies were conducted for six weeks in three persons on corn or wheat diets, which provided 38 or $43 \mathrm{gm}$. of protein, 5.5 or $6.0 \mathrm{mg}$. of niacin, 0.3 or 0.5 gm. of tryptophane, and about 2500 calories, $0.7 \mathrm{mg}$. of thiamine and $0.5 \mathrm{mg}$. of riboflavin daily (calculated). The corn diet included $190 \mathrm{gm}$. of degerminated corn meal and grits and $60 \mathrm{gm}$. of white unenriched flour; the wheat diet, $250 \mathrm{gm}$. of the white flour. The urinary excretion of riboflavin and thiamine decreased rapidly on the basal diets and remained low throughout the experiment, while that of niacin was unchanged. The daily output of $\mathrm{N}^{1}$ methylnicotinamide was $2 \mathrm{mg}$. or less on the wheat diet and decreased further on the corn regimen. After ten days of the basal corn or wheat diet, $5 \mathrm{gm}$. of dl-tryptophane was administered daily for 8 days. This resulted in an increased daily excretion of 6 to $12 \mathrm{mg}$. of $\mathrm{N}^{1}$ methylnicotinamide.

A test dose of niacin, thiamine, and riboflavin was given at the end of the tryptophane experiment. The urinary excretion of $\mathrm{N}^{1}$ methylnicotinamide was normal, of riboflavin, low normal and of thiamine, very low in two and normal in one patient. No signs of vitamin B complex deficiency developed and no significant change in serum proteins or in the blood picture occurred during this study.

Findings suggest that tryptophane is an important precursor of niacin in humans and may contribute to the body stores of this vitamin.

Studies of Immunity in Brucellosis: The Bactericidal Action of Human Blood Against Brucella. WENDELL H. Hall (by invitation) and Wesley W. Spink, Minneapolis, Minn.

The information available concerning the role of humoral antibodies in brucellosis is confusing. The present study has revealed that the killing action of normal human blood for Brucella does not require the presence of leukocytes. The effective antibody in serum is heatstable, and complement is necessary for its optimum bactericidal action on Brucella. Br. abortus (16 strains) was more readily killed than $\mathrm{Br}$. suis (3 strains) or $\mathrm{Br}$. melitensis (1 strain).

Bactericidal tests were performed by adding serial dilutions of Brucella to standardized amounts of fresh serum and incubating the mixtures for 24 hours. No killing of $\mathrm{Br}$. abortus was obtained with sera from 10 in- fants 4 to 16 months of age. Sera from older children had the same action as those from adults. Forty-five adult sera killed 18 to $180,000 \mathrm{Br}$. abortus cells (strain 524) per ml. of serum (median 15000). Twenty-eight sera without agglutinins for Brucella from 14 individuals having dermal hypersensitivity for Brucella killed 18 to $18,000 \mathrm{Bru}$ cella (median 5000). The bactericidal power of 89 sera containing agglutinins from 26 patients having positive intradermal Brucella tests but no demonstrable bacteremia ranged from 0 to $1,800,000$ (median 500). Forty-six sera from 13 patients having bacteremia due to $B r$. abortus killed only 0 to 180 organisms (median 36 ). The low bactericidal action of the latter group exhibited a pro-zone phenomenon in that the action was greatly increased by diluting out the sera and adding infants' sera for complement. This pro-zone phenomenon appears to be due to an excess of antibody. The killing action of normal sera having a high bactericidal titer is inhibited by the addition of sera from patients with bacteremia.

\section{Pathogenesis of Pneumonia Secondary to Influenza. Cart G. Harford and (by invitation) HeLen V. LeIDler, St. Louis, Mo.}

Mice with sublethal influenza viral infection of the lung succumb more readily than normal mice to bacterial infection induced by inhalation of fine droplets containing pneumococci. A study of this phenomenon was designed to elucidate principles applicable to the general problems of respiratory infection.

Although it is known that marked multiplication of virus occurs in the lungs of mice within twenty-four hours after inoculation, microscopic lesions from the virus are not present at this early stage. On the other hand, histological lesions in the lung due to viral action are fully developed five days after inoculation.

Bacterial counts of the left lobes of the lungs of normal mice have shown a marked reduction in the number of pneumococci within six hours after inhalation and a similar reduction has been found in mice with twenty-four hour viral infections. In contrast, bacterial counts of the lungs of mice with five day viral lesions have demonstrated growth within six hours.

These observations indicate that the effect of the virus in lowering resistance to secondary bacterial infection is not dependent on the presence or multiplication of the virus in pulmonary tissue but is associated with the histological lesion produced by viral action.

The Pathogenesis of Circulatory Failure in Rocky Mountain Spotted Fever: Alterations in the Blood Volume and Thiocyanate Space at Various Stages of the Disease. George T. HARRell and (by invitation) Jerry K. Airawa, Winston-Salem, N. C.

Previous investigation has shown that peripheral circulatory collapse in Rocky Mountain spotted fever is accompanied by a drop in serum proteins and the development of generalized edema.

Serial determinations of the blood volume and "extravascular thiocyanate space" were done at intervals during the course of the disease, and were compared with the 
serum protein levels and with the intake and output of fluid. The blood volume was found to drop simultaneously with an increase in thiocyanate space; the magnitude of the alteration in the thiocyanate space was greater than that in the blood volume. These changes occurred between the tenth and the twelfth days of rash, and could be correlated with the clinical severity of the disease; a return to normal values took place early in convalescence, and was accompanied by diuresis.

The drop in serum proteins was preceded by an increase in urinary nitrogen excretion and could be partially alleviated by a very high-protein diet. Capillary permeability was altered in the disease, so that protein, electrolytes, and water escaped into the interstitial spaces. These changes occurred in 6 patients who received specific therapy in the form of hyperimmune antiserum or PABA, as well as in 7 patients who received supportive therapy only.

Similar alterations in blood volume and thiocyanate space have been produced experimentally in rabbits with serum sickness. An allergic mechanism may be responsible for the alteration of capillary permeability, although allergy in rickettsial diseases has not yet been demonstrated. Proper replacement of protein and the avoidance of excessive administration of crystalloids should help to prevent circulatory and respiratory failure. These principles of supportive therapy are probably applicable to other infectious diseases.

\section{Penicillin Protection Against Bacterial Endotoxins.} Walter D. Hawk and Alden K. Boor, Chicago, Ill. (introduced by C. Phillip Miller).

Penicillin provides a certain degree of protection for mice against intraperitoneal injections of the endotoxins of several gram negative bacteria.

The endotoxins against which a penicillin effect has been demonstrated have been prepared from meningococcus, gonococcus S. Paratyphi A., S. Paratyphi B., Shigella paradysenteriae, S. Enteriditis, S. Aertrycke and A. Aerogenes. Organisms are grown on solid media, harvested, washed in saline, lysed by dilute alkali ( $\mathrm{pH} 8.0$ ) sterilized by heat and finally cultured for proof of sterility. Graded doses of this endotoxin are given to mice intraperitoneally in order to determine its LD50 respectively for penicillin-treated and for untreated mice.

It is evident from a careful review of the data, that when penicillin is given in adequate amounts during the period preceding and shortly after endotoxin, a definite increase in LD50 follows.

Injection of control mice with the various materials used as vehicles for penicillin affords no protection.

Autopsy cultures of a representative number of mice have given no evidence of terminal infections to account for the higher mortality among controls.

Protection has evidently been provided, by means of penicillin administration against the endotoxins of all of the above named organisms. This result has not been apparent with the endotoxin of Shigella Shigae nor with several non-bacterial poisons tested.
The mechanism of this effect of penicillin cannot at present be explained.

Study of Folic Acid for Maintenance Therapy in Pernicious Anemia. Robert W. HeINLe and (by invitation) Janet T. Dingle and Austin S. Weisberger, Cleveland, Ohio.

Forty-one patients with pernicious or allied anemia were maintained on folic acid therapy for periods to one year. In 32 patients followed longer than six months, hematologic relapse occurred in nine who received intramuscular injections of 50 or $150 \mathrm{mg}$. at three- to six-week intervals. Relapse did not occur in any patient receiving daily oral doses of 10 to $40 \mathrm{mg}$.

Hematologic improvement occurred in six of the 41 patients. Three received daily oral therapy and three were given 45 or $50 \mathrm{mg}$. intramuscularly every two or four weeks.

Six patients in relapse responded adequately and have been maintained in good hematologic remission with folic acid.

Three of the 41 patients developed neurologic relapse while in hematologic remission. This complication was explosive and rapidly progressive in one. Liver extract therapy arrested the neurologic relapse in these patients.

It is concluded that daily oral therapy with ten or more mg. of folic acid maintained hematologic remission in these patients whereas intermittent intramuscular therapy permitted relapse in some cases. The occurrence of neurologic relapse indicates that folic acid is not a complete substitute for liver extracts, so that the latter must remain the treatment of choice for pernicious anemia.

\section{Arterial Catheterization of the Left Ventricle, Left Auricle, and Pulmonary Vein. HARPER K. Hellems* (by invitation), LewIS DExter and (by invitation), Florence W. Haynes, Boston, Mass.}

Venous catheterization has made possible exploration of the right side of the heart and pulmonary artery, but has not been applicable to investigation of the dynamics of the left side of the heart and pulmonary vein. In the past, these chambers have been almost immune to investigation except by difficult and time-consuming procedures.

In the present study, a No. 6 French radiopaque catheter, with a curved tip as used for venous catheterization, has been introduced into the carotid artery of anesthetized dogs and guided fluoroscopically into the aorta, left ventricle, left auricle, and pulmonary vein. This may be accomplished without a change of respiratory rate, pulse rate, and arterial blood pressure. Although it is usually an innocuous procedure, damage to valves and endocardium has sometimes occurred. It has, therefore, not been deemed safe in patients.

In animals, changes in the pressure dynamics of the left side of the heart and pulmonary vein under conditions of cardiac stress will be discussed.

\footnotetext{
* Life Insurance Medical Research Fellow.
} 
Changes in the Efficiency and Dynamics of Respiration in Experimental Congestion of the Lungs. HowARD E. Heyer, James Holman and George T. Shires,* Dallas Texas (Introduced by Ben Friedman).

Experimental pulmonary congestion was produced in dogs by rapid venous infusion of 0.9 per cent solution of sodium chloride or by sodium chloride-sodium bicarbonate buffer solutions. Intrapleural pressure fluctuations increased markedly in total amplitude while mean intrapleural pressure rose toward atmospheric levels, and intrapleural pressure during expiration rose above atmospheric in every animal. Respiratory efficiency was determined by the tidal exchange produced for each centimeter change in intrapleural pressure. Efficiency of respiration and tidal exchange fell progressively with venous infusion, and rose rapidly when hyperpnea was induced by carbon dioxide inhalation. The changes accompanying pulmonary congestion were constant and were independent of alterations in hydrogen ion concentration or serum $\mathrm{CO}_{2}$ tension. Vagotomy prevented acceleration of breathing during venous infusion but did not prevent the marked decrease in respiratory efficiency. Active participation of expiratory muscles was necessary to achieve optimal tidal exchange in the congested lung, since abolition of expiratory movements by lower cervical cord section caused marked diminution in tidal exchange. These findings were interpreted as being due to a marked increase in rigidity of the congested lung, so that tidal exchange was accomplished at the expense of a marked increase in activity of respiratory muscles, with a total greater change in intrapleural pressure. During extreme pulmonary congestion, even though intrapleural fluctuations increased markedly, tidal air diminished sharply, suggesting that (in addition to rigidity of the lung) alveolar space was encroached upon by the congested capillaries, or that the alveolar space was diminished in size by transudation of edema fluid.

Serum Sickness Due to Crystallized Bovine Albumin. James T. Heyl (by invitation) and Charles A. Janeway, $\dagger$ Boston, Mass.

During experiments to test the possible value of albumin crystallized from bovine plasma by the method of Cohn and Hughes as a possible blood substitute, there was an opportunity to observe a severe and rather unusual form of serum disease in twenty-four patients. An intravenous dose of 25 grams of albumin was given to a group of 60 volunteers. Twenty-four of these developed symptoms. The striking clinical features of the disease were as follows: (1) long incubation period (10 to 33 days); (2) variation in severity from a very mild illness to a protracted one (4 to 6 weeks) with high fever; (3) the

* Done during the tenure of a Life Insurance Medical Research Student Fellowship.

$\dagger$ This work was done under a contract recommended by the Committee on Medical Research between the Office of Scientific Research and Development and Harvard University. frequency of purpura, signs of hepatic and renal damage, and cardiac symptoms with electrocardiographic changes. Death occurred in one instance, and necrosis of the myocardium was found.

Immunological studies in the whole group indicated that bovine serum albumin, in man, as in experimental animals, is a relatively poor antigen in terms of its capacity to induce the formation of antibodies detectable by either the skin test or the precipitin test. In normal humans, as in animals, bovine albumin disappears very slowly from the circulation, whereas in certain instances of serum disease its disappearance was greatly accelerated. In some cases of severe serum sickness, recovery occurred before the disappearance of the bovine albumin from the circulation and antibodies never appeared. The relationship of the symptoms in the patients to the immunological phenomena will be discussed, as this experience with a disease caused by a measurable foreign protein without the power of multiplication raises many interesting questions concerning the pathogenesis of infactious diseases due to living agents.

Effect of Anxiety on the Cardiac Output. JoHN B. Hickam, and Walter H. Cargill, Atlanta, Ga., (Introduced by Julian Ruffin).

Anxiety causes a marked increase in cardiac output. Twenty-three unselected medical students were studied immediately before and 24 hours after an important academic examination. As measured by the ballistocardiograph, the group showed an increase in cardiac output of approximately 50 per cent over the composed level. The greastest increase was 180 per cent.

Studies with the technique of intracardiac catheterization measuring the cardiac output by the Fick Principle were carried out on hospital patients. Anxiety was spontaneous or induced by suggestions; relative composure was obtained by reassurance, with or without light sedation. The data demonstrated that anxious individuals at rest may maintain a cardiac output which is much in excess of composed individuals, but without a corresponding increase in oxygen consumption. If an anxious person does sufficient work to increase the oxygen consumption to a level of 250 to $400 \mathrm{cc}$. per minute per square meter, the cardiac output may not be increased. Indeed, in certain subjects light work may cause the output to fall below that present in the resting but anxious state.

Studies on patients with left ventricular failure demonstrate that stimulus (work) which normally increases the cardiac output does not have this effect in severe heart failure. Instead the pulmonary pressure rises, presumably because of damming up of blood behind the failing left ventricle.

Reflex stimuli normally resulting in an increase in cardiac output would be expected to cause in patients with left ventricular failure a rise in pulmonary pressure. This offers a rational explanation for the precipitation of attacks of acute pulmonary edema by emotional stimuli and by reflex stimuli from the pleura or peritoneum during the removal of fluid by paracentesis. 
Streptomycin; an Antibiotic Effective Against Some Forms of Clinical Tuberculosis. H. C. Hinshaw and (by invitation) W. H. Feldman, Rochester, Minn.

The present status of streptomycin therapy in experimental tuberculosis of guinea pigs under varying conditions is briefly described and evidence presented to indicate that this drug is a highly effective antibacterial agent, even when utilized under unfavorable experimental conditions. The clinical possibilities and limitations of streptomycin for treatment are discussed briefly. Evaluation is based on experience with treatment of approximately 125 patients with different types of tuberculosis during the previous two and a half years. Clearly recognizable therapeutic effects are noted in many types of the disease, including tuberculous meningitis; miliary tuberculosis; progressive, exudative pulmonary tuberculosis; ulcerating tuberculous lesions of the larynx, trachea and larger bronchi; tuberculous draining sinuses, and tuberculosis of the genito-urinary tract. The effect of streptomycin appears to be limited to a suppression of the infectious process. The permanence of results may depend on whether or not natural healing may be achieved during the few months of effective action prior to the appearance of drug-resistant strains of Mycobacterium tuberculosis.

\section{Extent of Vasodilatation Induced in Different Vascular} Beds After Systemic Autonomic Blockade with Tetraethylammonium. S. W. Hoobler, Rosalie B. NEligh, Gordon K. Moe, S. Don Malton, Saul Cohen, and $H$. T. Ballantine, JR., (by invitation) and $R$. $H$. Lyons, Ann Arbor, Mich.

In normotensive and hypertensive subjects injection of tetraethylammonium results in a temporary decrease in the total peripheral resistance as manifested by a reduction in mean arterial pressure and a maintained or increased cardiac output. The blood flow through vascular beds believed to be normally under some degree of vasomotor tone is markedly increased. The volume flow of blood in the hands and feet as measured by the venous occlusion plethysmograph increases significantly above resting levels following the administration of $500 \mathrm{mg}$. of the drug and exceeds the levels achieved by other vasodilating drugs and may occur despite a marked decrease in arterial pressure. Blood flow seldom reaches the levels seen after sympathetic block with metycaine or after heat to the trunk, suggesting that a complete autonomic blockade is not produced. On the other hand there is a rise in cutaneous circulation as judged by increase in skin temperature of the hands and feet frequently with abolition of the temperature gradient. After sympathetic denervation of the extremity the blood flow is not further increased by administration of this drug. Induced vasoconstrictor reflexes in the hands and feet are reduced or abolished after tetraethylammonium. Blood flow in the forearm is only slightly increased after administration of the drug. Renal blood flow as measured by para-amino hippurate clearance is unaffected despite variable reductions in arterial pressure in hypertensive and normal subjects. It is suggested that increase in blood flow through various vascular beds following tetraethylammonium depends on the presence of neurogenic vasoconstrictor tone in these areas.
Sickle Cell Anemia. I. The Structural Defect of the Erythrocytes in Sicklemia. William H. Kelly and (by invitation) P. K. Switzer, Grorge Mangan, William M. McCord and B. F. Culp, Charleston, S. C.

Preliminary studies are in process of completion to show that the error of construction of erythrocytes in sicklemia resides in the cell membrane or stroma.

The erythrocytes in sicklemia exhibit an increased hematocrit value when reduced, whereas, with normal red cells the reading is equal or tends to be reduced under the same conditions.

An analysis of samples shows the increase in the hematocrit value of reduced sicklemic erythrocytes is attended by at least a proportionately greater amount of intercellular fluid. This indicates that the reduced red cells of sicklemic blood are not of increased size but possess a greater viscosity than oxidized normal or sicklemic erythrocytes.

A comparison of the cell shadows from laked sicklemic and visual erythrocytes by the above technic showed apparently identical differences.

Cerebral Blood Flow and Metabolism in Diabetic Acidosis and Coma. Seymour S. Kety, B. David Polis, CArI S. Nadler and CARL F. Schmidt, Philadelphia, $\mathrm{Pa}$. (Introduced by Isaac Starr).

Quantitative measurement of cerebral blood flow and metabolism of 13 patients in profound diabetic acidosis or coma was made by means of the nitrous oxide method. On admission the mean values for blood glucose, arterial $\mathrm{CO}_{2}$ content, and arterial pH were $560 \mathrm{mg}$. per $100 \mathrm{cc}$., 12 volumes per cent and 7.06 respectively. No significant differences with respect to age, blood $\mathrm{pH}, \mathrm{CO}_{2}$, glucose electrolyte patterns or cerebral blood flow were demonstrable between patients who recovered and those who succumbed. Those who recovered exhibited higher cerebral oxygen consumption, better mental function, higher blood pressure and lower blood ketone concentration. A reduction in cerebral oxygen consumption of 40 per cent from the normal was associated with failure to respond to treatment and death within 12 hours. These data, hitherto unobtainable, permit an evaluation of numerous factors held to play a role in the cerebral depression and frequent irreversibility of this condition. Correlation of cerebral oxygen consumption with some of these functions reveals the following: poor correlation with blood glucose, $\mathrm{CO}_{2}$, total base or chloride concentrations, or with cerebral blood flow; a just significant correlation with arterial hydrogen ion activity $\left(r=0.43 \pm \sigma_{r} 0.187\right)$; the best correlation was obtained with blood ketone concentration $\left(r=-0.65 \pm \sigma_{\mathrm{r}} 0.132\right)$.

The Rate of Conduction in the Human Atrium. C. E: Kossmann, and (by invitation) A. R. Berger, J. Brumlik and S. Briller, New York, N. Y.

The classical experiments of Lewis and his associates in which they demonstrated that the rate of electrical conduction in the dog's atrium is $1,000 \mathrm{~mm}$. per second were repeated, with modifications, in man.

By means of two string galvanometers and an electrode passed into the right atrium through an antecubital vein, 
intraatrial potentials at various levels between the cavae were recorded simultaneously with a standard lead. Distances between levels were measured radiographically by two techniques. Times of intrinsic deflections were measured using a fixed wave in the simultaneous lead as a reference point. In three men with normal sized hearts the calculated rates of conduction in the right atrium were 2,275 mm. 2,666 mm. and $1,866 \mathrm{~mm}$. per second respectively.

Assuming that the spread of excitation through the atria is uniform and knowing that the mean duration of the $P$ wave in the human electrocardiogram is $0.08 \mathrm{sec}-$ ond, the distance from the region of the sino-auricular node to the farthest reaches of the atria, most probably the tip of the left atrial appendage, is calculated to be approximately $18.5 \mathrm{~cm}$. Measurements on models, on crosssectional anatomical drawings, and on fresh human hearts at necropsy indicate that the distance in question is approximately 15 to $22 \mathrm{~cm}$., and that the anatomical considerations are in accord with the physiological observations.

The conclusion reached is that in a sinoatrial rhythm electrical excitation travels two or more times faster in the human than in the canine atrium.

Calcinosis, Scleroderma and the Anti-Stiffness Factor. John Lansbury, Rosalind Wulzen, Lawrence W. Smith and William J. van Wagtendonk, Philadelphia, Pa. (Introduced by Richard A. Kern).

The anti-stiffness factor was detected by Wulzen and Bahrs in greens and isolated from raw cream and cane juice by van Wagtendonk and Wulzen. Guinea-pigs lacking it develop muscular stiffness and degeneration and eventually deposits of calcium between muscle fasciculi, around joints, under the skin and in parenchymal organs. The anti-stiffness factor reverses the early changes. It appears to be a regulator of phosphorus metabolism.

This communication describes the roentgen appearance of the calcifications and compares them with the deposits found in human calcinosis. Striking similarities to both circumscribed and interstitial types are noted. (These are associated with scleroderma and dermatomyositis in humans.) The lesions induced by excess vitamin $D$ are compared and excluded as the cause of both animal and human lesions.

Since the lesions induced at will in guinea-pigs by deficiency in the anti-stiffness factor are roentgenographically identical with those of human calcinosis, we postulate that a deficiency of this or similar substances may be one of the factors in the pathogenesis of human calcinosis and possibly scleroderma and dermatomyositis.

The Effects of Radiation on Hemopoiesis. Is there an Indirect Effect? JOHN S. LAWRENCE and (by invitation) William N. Valentine and Andrew H. Dowdy, Rochester, N. Y.

Twenty-six successful cross circulation experiments (carotid-to-carotid anastomoses) were performed between a normal cat and one which had received $1500 \mathrm{r}$ whole body radiation at some interval up to eighty-two hours before cross circulation. In seven experiments, one animal was radiated at the time the carotid anastomoses were functioning, the normal partner being shielded during radiation. The total and differential leukocyte counts of the normal cat were followed for approximately twentyeight days after cross circulation was discontinued.

The data were not considered to support the thesis of indirect effects peculiar to radiation mediated via the circulation. A trend toward slightly lowered absolute lymphocyte counts in normal animals after cross circulation was not considered significant and in no instance did leukopenia develop in the normal animal. A review of the medical literature revealed no convincing support for indirect radiation effects.

The clinical impression that leukopenia results in humans given repeated radiation either over non-hemopoietic tissue or over very limited amounts of hemopoietic tissue needs to be very critically reviewed.

Clinical Hypoprothrombinemia: $A$ Study of Factors $A$ and $B$ of Prothrombin. Jessica H. Lewis and IvaN L. Bennetr, JR., Atlanta, Ga. (Introduced by Eugene A. Stead, Jr.).

Clinically, hypoprothrombinemia may be due to one or more of the following causes: (1) vitamin $\mathrm{K}$ deficiency, due to poor diet or poor absorption, (2) severe liver damage, (3) administration of drugs (dicoumarol and salicylates), and (4) idiopathic or unexplained hypoprothrombinemia.

Quick (1943) and Feissly (1943) have shown that the prothrombin reaction is dependent upon the presence of at least two substances in normal plasma. Factor $A$ is reduced by aging or heating plasma and Factor $B$ is reduced in vivo by administration of dicoumarol or in vitro by absorption with aluminum hydroxide or barium sulfate. Standard methods of preparing Factor A and Factor B plasma are presented and attempts are made to characterize these factors by the effects of heat, $\mathrm{pH}$, and $\mathrm{Ca}^{++}$ ion on each. Employing preparations of these factors, studies were made on plasma obtained from patients with the various types of prothrombin deficiencies.

As examples of each type of prothrombin deficiency patients manifesting symptoms of obstructive jaundice, Laennec's cirrhosis, dicoumarolization, and idiopathic hypoprothrombinemia are presented.

Our patient suffering from idiopathic hypoprothrombinemia is unique in our experience and among the rare published cases. The onset was abrupt at age 29 with almost complete disappearance of Factor B of prothrombin, the Quick prothrombin time being prolonged to $10 \mathrm{~min}$ utes with a whole blood coagulation time prolonged to 60 minutes. Fibrinogen and formed elements of the blood were normal. The patient received massive dosage of vitamin $\mathrm{K}$, with simultaneous return of circulating prothrombin. Under observation she has maintained normal prothrombin without treatment for 60 days.

In all four types of prothrombin deficiency there was demonstrable a similar defect, that is, reduction of Factor B with apparently normal Factor A. Administration of vitamin $\mathrm{K}$ either as synthetic 2-methyl-1,4-naphthohydroquinone-diphosphoric acid ester tetrasodium salt 
(synkavite) or 2-methyl-3-phytyl-1,4-naphthoquinone (viamin K-1) caused rapid regeneration of Factor B unless severe liver damage was present.

These investigations suggest that vitamin $\mathrm{K}$ is necessary for the formation of Factor B of prothrombin. Since no clinically demonstrable deficiency of Factor A was found in these patients, the role of vitamin $\mathrm{K}$ in relation to this factor is problematic.

The Direct Isolation of Mumps Virus in Chick Embryos. Glen R. Leymaster and Thomas G. Ward, Baltimore, Md. (Introduced by Thomas B. Turner).

Successful direct isolation of mumps virus has not been reported in this country, so far as the authors are aware. Mumps virus has been isolated in this laboratory by chick embryo inoculation, from 4 of 5 patients ill with parotitis during the first four days of illness. Two of these strains have been inoculated into monkeys, which developed clinical and serological evidence of mumps. Each strain was re-isolated from monkey parotid by embryo inoculation.

Penicillin and streptomycin are added to the patient's saliva to a final concentration of 250 and 2500 units per milliliter, respectively. One-tenth milliliter of the salivaantibiotic mixture is then inoculated into the amniotic sac of seven day old embryos.

After seven days incubation at $35^{\circ} \mathrm{C}$., amniotic fluid and membranes are removed. The fluid is tested by chick cell hemagglutination. Positive fluids are re-inoculated. The amniotic membranes of negative specimens are ground with their respective amniotic fluids, and re-inoculated. Three passages are carried out before a specimen is considered negative.

Identification of the virus as mumps is accomplished by hemagglutination inhibition and complement fixation tests, using amniotic fluid as antigen.

Further laboratory studies, including neutralization tests in embryos, are now in progress.

Fluorometric Measurement of Plasma Quinidine and its Correlation with Cardiac Effects in Man. ARTHUR J. Linenthal, Stanley Ulick and Lawrence A. PatTERson, Boston, Mass. (Introduced by Joseph E. F. Riseman).

Measurement of the fluorescence of quinidine provides a simpler and more sensitive means of determining its concentration than has previously been available.

In man, within fifteen minutes after a single oral dose, quinidine can be detected in the plasma. Maximum levels are reached in 1 to 3 hours and may be maintained for 2 to 3 hours. Appreciable amounts remain after 8 to 12 hours. Average peak concentrations after single doses of $0.2,0.4$ and $0.6 \mathrm{gm}$. are, respectively, $0.8,1.3$ and 2.0 mg. per liter.

When the same dose is repeated every two hours, i.e. at the peak response to the preceding dose, the concentration increases with the first four or five doses only. A further increase in concentration can be attained more effectively by increasing the size of the individual dose than by increasing the frequency of administration.

When the same dose is repeated every 6,8 or 12 hours, peak concentrations are similar and do not increase.
With the more frequent administration the level is better maintained between doses.

Suitable plasma concentrations for the therapy or prophylaxis of cardiac arrhythmias can thus be attained by planned doses according to one of the general schedules described above.

Plasma concentrations parallel closely the effect on the heart as measured by the rate of oscillations in auricular fibrillation, and by the Q-T duration. This correlation affords a new quantitative approach applicable to the clinical and pharmacological study of this cardiac drug.

The Application of the Isotope Technique to the Study of the Rates of Formation of Blood Constituents in Man. Irving M. London, David Shemin, and D. RittenBERG, New York, N. Y. (Introduced by R. West).

The feeding of glycine labeled with $\mathrm{N}^{15}$ to humans results in the incorporation of $\mathrm{N}^{15}$ in the serum proteins and the heme of red blood cells as well as in other body constituents. Glycine is the nitrogenous precursor of the protoporphyrin of hemoglobin. The $\mathrm{N}^{15}$ is incorporated in the red blood cell during the deposition of hemoglobin, and the labeled porphyrin remains in the cell until the cell disintegrates. The porphyrin is not subsequently reutilized for hemoglobin synthesis. Acçordingly, the isotope technique affords a unique method for studying the kinetics of red cell formation and for determining the average life span of the human red cell. This life span has been found to be 127 and 128 days in two normal adult men. Data on the rates of generation and on the life span of red cells in a patient with pernicious anemia and in another with polycythemia vera have been obtained which may clarify certain factors in these disease processes. Serial measurements of $\mathrm{N}^{15}$ concentration in electrophoretically separated fractions of serum proteins have yielded information on the relative rates of elaboration of these proteins. Correlative studies of $\mathrm{N}^{16}$ concentration in urinary urea, ammonia and uric acid have provided further information on protein and purine metabolism.

The Relation of the Rh Factor in Cirrhosis of the Liver. Frank S. Lovingood, Philadelphia, Pa. (Introduced by Franklin R. Miller).

Of the various factors listed as contributing to the production of cirrhosis of the liver, erythroblastosis fetalis and the familial tendency are probably mentioned least often. One is able to find several reports of each type in the literature.

Recently twenty cases of cirrhosis of the liver have been studied; 45 per cent or nine patients were found to be $R h$ negative and 55 per cent or eleven patients were $R h$ positive. The percentage of $\mathrm{Rh}$ negative patients seems significant.

Cirrhosis that follows icterus gravis neonatorum is probably due to an antigen antibody reaction. The mother forms antibodies against the $\mathrm{Rh}$ agglutinogen of the fetus. The antibody passes into the fetal circulation resulting in hepatic damage.

The development of the $\mathrm{Rh}$ negative and familial cirrhosis may be identical in that the development may be 
due to incompatibility between a $\mathrm{Rh}$ positive mother and a $\mathrm{Rh}$ negative fetus. Infants born under such circumstances, as well as those born with icterus gravis neonatorum, probably begin life with decreased hepatic reserve and, therefore, are more prone to develop clinical cirrhosis of the liver later in life. The time of development will depend on the degree of initial damage, as well as the degree of further damage from infection, ingestion of alcohol or poor dietary measures.

A Study of the Mechanism of Nephrotic Edema. Jов N A. Luetscher, JR., Baltimore, Md.

The association of hypoproteinemia, sodium retention, and edema in nephrosis is well known, but the fundamental mechanisms leading to these manifestations are obscure. The decreased colloid osmotic activity of the plasma may facilitate the development of edema, but is not necessarily related to the presence or absence of clinical edema.

The repeated administration of concentrated human serum albumin to patients with nephrosis increases the concentration of albumin and the colloid osmotic activity of plasma. The consequent large shift of fluid into the plasma minimizes the rise in protein concentration despite the greatly increased circulating protein. These impressive circulatory changes are followed by smaller and sometimes ineffectual changes in the renal excretion of salt and water. The glomerular filtration rate is generally increased, and the proportion of sodium reabsorbed is greatly diminished. The moderate diuresis of sodium is not necessarily correlated with increased urine flow or with excessive proteinuria, and is not reproduced by the administration of mannitol, an osmotically active and unreabsorbed substance.

Spontaneous diuresis in nephrosis is distinctively different from the diuresis induced by the administration of albumin in that the plasma volume and protein concentration may change only slightly during a spontaneous diuresis, while the proportion of sodium reabsorbed by the renal tubule is diminished even more than after albumin therapy.

It is concluded that the reabsorption of an excessive proportion of sodium by the renal tubule is responsible for the intractable edema of nephrosis, and that the restoration of the total circulating protein to nearly normal levels does not immediately lead to diuresis. The relationships between hypoproteinemia, edema, and renal function are being further investigated.

The Pharmacologic Promotion of Evacuation from the Post-Vagotomy Retentive Stomach. Thомas E. Machella and (by invitation) Horace H. Hodges and Stanley H. Lorber, Philadelphia, Pa.

One of the complications which had developed following section of the vagus nerves for peptic ulcer has been gastric retention. This has occurred especially in those patients who have not had a gastroenterostomy or who do not have an adequately functioning one. For the relief of retention, additional surgery, some form of gastroenterostomy, has had to be performed.

It has been found possible to avoid surgery in each of six patients with post-vagotomy gastric retention by promoting gastric evacuation by means of the parasympathomimetic drug, urethane of B-methyl choline (Urecholine).

The drug is administered orally after each of the main meals of the day in dosage of 6 to $10 \mathrm{mg}$. The patients have remained free of symptoms of retention while taking the drug but not when a "placebo" was substituted. Within 5 to 10 minutes of a subcutaneous injection of a 5 to $10 \mathrm{mg}$. dose, peristaltic activity in the antrum of the stomach can be demonstrated roentgenologically or by means of a recording balloon. The drug does not give rise to a significant increase in free hydrochloric acid providing the patient is permitted to swallow saliva or if the stomach contains neutralizing food substances.

Osmotic Factors Influencing the Formation of Ascites in Patients with Laennec's Cirrhosis of the liver. Harold Mankin and Alice Lowell, New York, N. Y. (Introduced by Arthur J. Patek, Jr.).

Effects of experimental alteration of the colloid osmotic pressure of the plasma and ascitic fluid and of the intraperitoneal hydrostatic pressure were studied in 10 patients with cirrhosis and ascites. The colloid osmotic pressures of the plasma and ascitic fluid were measured directly in an Hepp osmometer. The ascitic fluid volume was measured by an adaptation of the Evans Blue dye technique.

In each patient the difference between the colloid osmotic pressures of the plasma and the ascitic fluid remained approximately constant through periods of 3 months to 1 year. Following (1) alteration of the intraperitoneal hydrostatic pressure by abdominal paracentesis, (2) increase of the colloid osmotic pressure of the plasma during mercurial diuresis, (3) decrease of the colloid osmotic pressure of the plasma after the oral administration of salt solution, or (4) decrease of the colloid osmotic pressure of the ascitic fluid by the intraperitoneal injection of physiological saline solution, there were temporary changes in the rates of fluid and protein exchange between the plasma and ascitic fluid which served to restore the pre-existing constant difference between the colloid osmotic pressures of the plasma and ascitic fluid.

The results are interpreted as consistent with the Starling hypothesis describing osmotic equilibrium between transudates and the plasma.

A Study of the Plasma and Tissue Globulins in Myelomatosis. Nicholas H. Martin, Boston, Mass. (Introduced by James L. Gamble).

In a patient with multiple myeloma, the total plasma proteins were estimated as 10.9 grams per $100 \mathrm{mls}$. plasma. By electrophoretic analysis, 65 per cent of the total moved with the mobility of $\gamma$-globulins. There was no apparent excess of $\alpha$ or $\beta$ globulins. This $\gamma$-globulin was separated from the other plasma proteins and compared with $\gamma$-globulin from normal human plasma. It moved as a discrete well-defined entity having a mobility of the order of $1.1 \times 10^{-3} \mathrm{~cm} / \mathrm{volts} / \mathrm{sec}$. Nevertheless it 
was heterogeneous in the ultracentrifuge, having a pattern quite unlike that of $\boldsymbol{\gamma}$-globulins obtained from normal plasma. Moreover, it precipitated from an acetate buffer, ionic strength, $0.01 \mathrm{mols} / \mathrm{L}$ and of $\mathrm{pH}$ 6.0. In this also it differed from $\gamma$-globulin from normal human plasma.

The patient died in hospital, and a diagnosis of multiple myeloma was confirmed at autopsy. Tumor tissue was taken at autopsy, frozen, washed free of blood, and saline preparations examined. Ultracentrifugal studies showed the presence of abnormal globulins similar to those identified in the plasma. Similar globulins, though in much smaller amounts, were identified in the splenic pulp. Examination of control tissues from a normal individual treated in the same way, gave no indication of the presence of these globulins.

It is suggested that the $\gamma$-globulin circulating in the plasma of patients suffering from myelomatosis is abnormal and arises from the tumor cells.

Streptomycin in the Treatment of Tuberculosis in $\mathrm{Hu}$ mans. Walsh McDermotT, CarL MUschenheim, and Susan Hadley, New York, N. Y. (introduced by David P. Barr).

Since January, 1946, a clinical and laboratory investigation of the treatment of tuberculosis in humans has been conducted. More than fifty patients have been treated with a uniform preparation of streptomycin sulfate. The drug was prepared from crystalline material and is believed to be at least 95 per cent pure. The experimental series includes fourteen patients with acute hematogenous tuberculosis or meningitis and approximately forty individuals with pulmonary disease. The majority of the latter infections were either caseo-pneumonic or predominantly exudative in type. Approximately two-thirds of the series have been observed for periods of six to twelve months after the institution of the antibacterial therapy.

The course of the infection before, during and after streptomycin therapy has been studied by frequent clinical, roentgenological and bacteriological observations. Histologic studies of the nature of the tuberculous lesions have been made on the tissues of five individuals who had received streptomycin for periods ranging between 90 and 300 days before death.

The in vitro streptomycin sensitivity of tubercle bacilli isolated from each patient at biweekly intervals has been determined in Dubos media. The development of in vitro drug resistance appeared after four to eight weeks of therapy in the majority of patients from whom tubercle bacilli could still be cultured at that time. A definite correlation was found between the streptomycin sensitivity of a patient's organism in vitro and the response of that particular infection to the continued administration of the drug.

The institution of streptomycin therapy was associated, in every instance, with a definite and sometimes dramatic effect upon the course of the tuberculous infection. In certain forms of the disease, notably in acute hematogenous tuberculosis, a high incidence of relapse resulted from the development of drug-resistant strains of tubercle bacilli. The most uniformly satisfactory results were observed in the treatment of early exudative infections, moderately or far advanced in extent and which were usually associated with thin-walled cavities.

"Forward Failure": The Mechanism of Cardiac Edema Formation in Subjects with Normal or High Cardiac Outputs. Arthur J. Merrill and Walter H. CarGILL, Atlanta, Ga. (Introduced by Paul B. Beeson).

Previously presented evidence favoring the forward failure concept of edema formation in advanced heart failure consists of the following:(1) Marked reduction in renal plasma flow and filtration rate which is independent of venous pressure levels and closely related to inadequacy of cardiac output. (2) Filtration rates below approximately $70 \mathrm{cc}$. per min. result in a critical reduction of the amount of salt and water presented to the tubules. (3) Almost complete reabsorption by the tubules occurs with a net retention of salt and water and consequent edema formation. The cause of edema in patients with low cardiac reserve, but an adequate resting cardiac output and renal function, has not been explained; nor has edema associated with a high cardiac output, as in thyrotoxic heart disease.

The present work deals with a study of the effect of light exercise on the renal blood flow of patients in whom light exercise would be expected to bring out inadequacy of cardiac reserve. It was necessary that they have a high enough renal plasma flow and filtration rate to make possible a demonstration of significant reduction with exercise. Seven of 10 cardiac subjects had a fall in filtration rate with exercise which approached the critical level of $70 \mathrm{cc}$. per min. Of 9 normal individuals, none had an appreciable fall in filtration rate, though a few showed a substantial decrease in renal plasma flow.

In thyrotoxicosis the cardiac output parallels the BMR. Eight thyrocardiac patients with mild and moderate failure showed no striking change in renal plasma flow and filtration rate. One with severe failure in the presence of a high cardiac output had marked diminution in renal blood flow and filtration rate; these rose to normal as the BMR fell. One other patient with severe failure had a low renal blood flow but the filtration rate was normal.

Thus it appears that while there is no fixed level of cardiac output at which the renal plasma flow and filtration rate fall, reductions may occur when the tissue demands exceed the ability of the heart to respond. If the filtration rate becomes sufficiently low, retention of salt and water (edema) occurs.

Possible mechanisms of the renal shutdown are mentioned.

Renal Blood Flow and Sodium Excretion Studies in Congestive Heart Failure.* Reuben Mokotoff and George Ross, New York, N. Y. (Introduced by Louis Leiter).

A study of the renal plasma flow, glomerular filtration rate, and sodium excretion in congestive heart failure was

* Aided by a grant from the Martha M. Hall Foundation and the Committee on Scientific Research of the American Medical Association. 
undertaken, since it has been postulated that cardiac edema is the result of failure of the kidney to excrete sufficient amounts of sodium and water. We found, in a series of 16 cases of chronic congestive heart failure due predominantly to rheumatic heart disease, that the mean "effective" renal plasma flow was 30 per cent and the mean glomerular flitration rate 65 per cent of normal. The mean filtration fraction was increased to 36.7 per cent as compared to $16.6 \pm 1.5$ per cent in our group of 14 normals. Five rheumatic cardiacs not in heart failure had normal glomerular filtration rates, renal blood flow and sodium clearances.

In 2 congestive failure cases in which 4 per cent sodium chloride was given, there was an excretion rate of 1 per cent and 1.5 per cent during the test period as compared to 7.4 per cent and 9 per cent in two normal patients under similar test conditions. The decreased sodium excretion found in congestive heart failure is due to a diminished filtration rate and not to an increased tubular reabsorption since the rate of reabsorption is the same for the cardiac in failure and for the normal and is a direct function of the glomerular filtration rate. It will be shown that the following equation expresses, as a first approximation, the relationship between the rate of tubular reabsorption $(T)$ and the glomerular filtration rate $\left(C_{m}\right)$ :

$$
T=P_{\mathrm{Na}} C_{m}
$$

where $P_{N a}$ Equals the plasma concentration of sodium and represents the slope of the line. Physiologically induced variations in the filtration rate from 100 to $219 \mathrm{cc}$. in the normal and from 60 to $90 \mathrm{cc}$. in the cardiac also reveals constancy in the rate of sodium reabsorption. This amounts to a mean of 13.3 millimols per $100 \mathrm{cc}$. of glomerular filtrate under our experimental conditions.

Our findings are consistent with the views as outlined by Stead and Merrill that in chronic congestive heart failure there is a decreased sodium load presented to the tubules for reabsorption, which fact is responsible for the series of events-increased blood volume, increased venous pressure-leading to cardiac edema.

Use of Chemotherapeutic and Antibiotic Agents in the Isolation of Viruses from Contaminated Sources. HERBERT R. MORGAN, Boston, Mass. (Introduced by Maxwell Finland).

This is part of a study designed to test the usefulness of certain chemotherapeutic and antibiotic agents as aids in the direct isolation of viruses in eggs from contaminated sources such as sputum, urine and feces. Psittacosis virus was used since it occurs in the nasal secretions and feces of its natural host. A standard preparation of seed virus was used throughout the study and varying dilutions of the virus and different amounts of the test agents were injected into the eggs by the yolk sac route.

Sulfadiazine and penicillin were found to inhibit the growth of the virus while streptomycin and tyrothrycin had no appreciable effect. Streptomycin alone and in combination with tyrothrycin was found useful for the isolation of psittacosis virus from fecal material on direct injection of eggs via the yolk sac route, both with virus added to normal human feces and from the feces of mice infected with psittacosis virus by the intravenous route. P-aminobenzoic acid and folic acid were found to counteract the inhibitory action of sulfadiazine, but had no effect on the multiplication of the virus. Cysteine $\mathrm{HCl}$ itself had no effect on the virus. When injected as long as 4 hours after the penicillin and virus, cysteine $\mathrm{HCl}$ inhibited the action of the penicillin on the growth of the virus.

A Study of Forty Patients Who Died in Liver Coma. T. L. Murphy, T. C. Chalmers and R. D. ECKhardT, Boston, Mass. (Introduced by George R. Minot).

A study is presented of 40 autopsied patients who died in coma within the past two years, all of whom had severe primary liver disease. The coma was precipitated by infection in seventeen, and hemorrhage in three. No extra-hepatic factor was found in the remaining twenty ("pure coma").

The clinical and liver function studies of the patients in "pure coma" did not differ significantly from their pre-coma studies nor from those of other patients with severe liver disease not in coma. The concentrations of blood non-protein nitrogen, glucose, chloride, carbon dioxide combining power, bilirubin, and phenols, although frequently abnormal, were not sufficiently altered to account for the coma. Determinations of plasma alpha amino nitrogen in comatose patients were normal.

Confusion and delirium for which sedatives were used often preceded the coma, and in six of the uncomplicated cases such sedation induced deep sleep which merged imperceptibly into coma.

Except in two patients in whom concentrated glucose temporarily lightened coma, the administration of intravenous dextrose, vitamin B complex, liver extract, protein hydrolysate and prophylactic chemotherapy failed to alter the coma. In the past two years there have been no patients with severe liver disease alone who recovered from coma. After prolonged treatment two have recovered from coma secondary to sedation. Two patients with infection which induced coma recovered after similar parenteral nutrition and control of infection.

It is concluded that although clinical and laboratory examinations do not elucidate the etiology of liver coma, sedation as well as infection and hemorrhage is an important contributing factor. Intravenous glucose, B complex vitamins, liver extract and protein hydrolysates are therapeutically supportive but are not specific analeptics.

Correlation of Electrocardiographic and Pathologic Findings in Infarction of the Lateral Wall of the Left Ventricle. Gordon B. MYers and (by invitation) Howard A. KLein and Bert E. Stofer, Detroit, Mich.

Lateral infarction was established by necropsy in ninety cases. Pathologic examination included coronary injection with radio-opaque mass, section by Schlesinger technique or transverse slices, roentgenogram, and multiple microscopic blocks. Standard limb and Wilson precordial leads were available in every case and Goldberger extremity leads were obtained in eighty cases. 
Anterior infarction extending into the lateral wall of the apex was found at necropsy in forty-six cases. Lateral extension was manifested by abnormal $Q$ waves in $V_{8, ~}$, and usually in $a V_{L}$, whereas infarction confined to the anterior wall was manifested by abnormal $Q$ waves in $V_{2,8}$, 4. Lateral extension from posterior infarction was found in twenty-five cases. A diagnosis of lateral extension could be made from $\mathrm{V}_{0}$ or $\mathrm{aV}_{\mathbf{L}}$ in eleven cases and of posterior infarction from $\mathrm{aV}_{\mathrm{F}}$ in seventeen of twenty cases. Primary lateral infarction was present in nineteen cases. Infarcts confined to the lateral aspect of the apex were recognizable from the pattern in $V_{b, 0}$ and $\mathrm{aV}_{\mathrm{L}}$, whereas those localized to the lateral aspect of the base could usually be suspected from $\mathrm{aV}_{\mathrm{L}}$ and confirmed by high precordial leads.

The infarct was generally maximal in or limited to the subendocardial layer and the thickness could be estimated from depth and duration of the $Q$ wave. Infarcts confined to the subepicardial layer were accompanied by abnormalities in the $T$, but not in the $Q$ wave.

The correlation of electrocardiographic and autopsy findings will be brought out by the presentation of illustrative cases.

Measurement of the Hepatic Blood Flow in Man. J. D. MYERs, Atlanta, Ga. (Introduced by W. M. Nicholson).

Measurement of the hepatic blood flow in normal males has been undertaken utilizing a method based on "the Fick principle" with urea as the test substance. The urea concentration has been determined in (1) femoral arterial blood, which has been assumed to have the same urea concentration as hepatic arterial and portal venous blood, and (2) hepatic venous blood which has been obtained by direct catheterization of the right hepatic veins by the procedure of Warren and Brannon. The urea determinations have been done by a modification of the urease methot of Van Slyke and Cullen with an accuracy of $\pm 0.2 \mathrm{mg}$. of urea per $100 \mathrm{cc}$. of blood. Urine has been quantitatively collected and assayed for urea by the same procedure.

In fasting, normal, young males, the arterial urea concentration has generally been constant over the period of study, i.e. about two hours. Accordingly, the urinary excretion of urea during this period is considered equal to the production of urea by the liver. The excretion of urea in the urine has varied between 12.1 and $16.4 \mathrm{mg}$. per minute, and the hepatic vein - femoral artery urea difference has ranged from 0.5 to $1.2 \mathrm{mg}$. of urea per $100 \mathrm{cc}$. of whole blood. The calculated hepatic blood flows per minute,

Urinary excretion (hepatic production) of urea per minute Hepatic vein - Femoral artery urea difference

range from 750 to $1,620 \mathrm{cc}$. per square meter of body surface. Concomitant determinations of cardiac output have shown these hepatic blood flows to represent 19 to 45 per cent of the entire cardiac output.

Estimated splanchnic oxygen consumptions (femoral artery - hepatic vein oxygen difference $X$ hepatic blood flow) vary between 27 and $77 \mathrm{cc}$. of oxygen per minute, which represents from 11 to 31 per cent of the total oxygen consumption at rest.
Comparison is made of the data for liver blood flow by the urea method with data obtained simultaneously by the bromsulphthalein method of Bradley et al.

The Improved Demonstration of Circulating Antibodies in Hemolytic Anemia by the Use of a Bovine Albumin Medium; Parallelism with Survival Time of Transfused Red Cells. JAcoB NeBer, Boston, Mass. (Introduced by William Dameshek).

Circulating antibodies were investigated in the sera of seventeen patients with various hemolytic syndromes by a modification of the tube agglutination technique in which 20 per cent bovine albumin solution completely replaced normal saline as a diluting and suspending medium.

In five cases of idiopathic acquired hemolytic anemia a circulating warm antibody was demonstrated with the albumin technique, although in four of these cases, antibody could not be demonstrated in a saline medium. Three patients with congenital hemolytic anemia not in crisis showed no antibody, but in one of these patients during a hemolytic crisis a warm autohemolysin was demonstrated in bovine albumin only.

Two patients with sickle cell anemia, two with severe Mediterranean anemia, one with acute hemolytic anemia caused by chemical exposure, one with paroxysmal nocturnal hemoglobinuria, two patients with hypersplenic hemolytic anemia, and one patient with the symptomatic hemolytic anemia of subacute lymphatic leukemia failed to show circulating antibodies.

Parallel determinations of the survival time of transfused red cells by the Ashby technique showed a distinct correlation with the presence of antibodies. The survival time was greatly diminished when antibodies were demonstrable. Performance of both types of tests proved of distinct diagnostic and prognostic value.

Studies on the Control of Hepatitis Virus in Blood and Blood Products. JoH N R. NeEFe, and (by invitation) Joseph Stokes, JR., Sydney S. Gellis, and Mercer A. Blanchard, Philadelphia, $\mathrm{Pa}$

The transmission of hepatitis viruses by intentional or accidental parenteral introduction of blood or its products is a serious current problem and promises to be one of equal, or possibly greater, importance in the future. Its present magnitude is indicated by the fact that the chiefs of service in some leading hospitals will no longer permit the use of pooled plasma (including the large supplies of surplus Red Cross plasma) in their patients. The obvious need for the development of methods for inactivation and control of the hepatitis viruses in blood or its products has led to the preliminary studies summarized herein.

1. In a cooperative study conducted in conjunction with the Harvard Plasma Fractionation Group, a serum hepatitis virus in human serum albumin solution apparently was inactivated, without rendering the albumin solution unsatisfactory for human use, by heating the experimentally contaminated albumin solution for 10 hours at $60^{\circ} \mathrm{C}$. after stabilizing it with acetyl tryptophane and sodium caprylate. As this method is compatible with large scale production, it appears that, until proved otherwise, human 
albumin solutions so treated can be considered free of the risk of virus hepatitis and that this valuable blood product, at least, could be salvaged safely from the large stores of pooled plasma suspected or known to be contaminated with a hepatitis virus.

2. The demonstrated protective effect of gamma globulin against infectious hepatitis has led to investigation of its protective effect against serum hepatitis. No protective effect was apparent when $10 \mathrm{ml}$. of gamma globulin and $2 \mathrm{ml}$. of plasma (known to contain a serum hepatitis virus) were injected simultaneously at separate intramuscular sites. No neutralizing or protective effect was apparent when $2 \mathrm{ml}$. of the plasma were mixed with $1 \mathrm{mt}$. of gamma globulin and allowed to stand for 4 hours at room temperature before intramuscular injection of the mixture into volunteers. The results of the clinical trials in army hospitals have suggested that quantity and/or time of injection may be important factors in the protective effect of gamma globulin against serum hepatitis. As the same factors might account for the lack of apparent protective effect in the experimental study described, these factors have been taken into consideration in a subsequent study now nearing completion. Twentyone volunteers have been injected with plasma known to contain a serum hepatitis virus. Thirteen to sixteen $\mathrm{ml}$. of gamma globulin have been injected at monthly intervals into 7 of these men starting 1 month after the plasma injection. Another 7 men serve as controls for the first group injected with globulin and for a third group of 7 men each of whom was injected with a mixture of the plasma and gamma globulin $(3 \mathrm{ml}$. plasma and $10 \mathrm{ml}$. of gamma globulin, mixed and stored for $3 \mathrm{hrs}$. at room temperature and for $24 \mathrm{hrs}$. at $4^{\circ} \mathrm{C}$ before injection). The results of this study will be presented and discussed together with the results of the studies outlined above.

The Effect of Coronamide in Inhibiting Penicillin Excretion. R. F. PARKER and (by invitation) R. ALBRIGHT, Cleveland, Ohio.

Penicillin injected intramuscularly or intravenously is rapidly excreted in the urine, largely as the result of renal tubular activity. A number of attempts have been made to increase the concentration of penicillin in the blood, and to prolong the effect of a given dose by suppressing the tubular secretion of the drug. Coronamide (4 carboxyphenyl-methane sulfonanilide) has recently been proposed as a nontoxic compound which specifically suppresses tubular secretion of penicillin. The present study is an attempt to evaluate its efficiency in routine clinical use in patients having normal kidney function, and in those suffering from various forms of renal disease.

$A$ Comparison of the Pressor Activity of Desoxycorticosterone Acetate in Normotensive and Hypertensive Subjects. George A. Perera and (by invitation) David W. Blood, New York, N. Y.

Previous studies demonstrated that desoxycorticosterone acetate (DCA), administered to patients without hypertension or adrenal disease, may be associated with increases in blood pressure. Significant changes were apparent only after several weeks of drug injection.
Observations were made on ten normotensive subjects and twelve patients with uncomplicated hypertensive vascular disease maintained on a constant regimen and after a preliminary baseline period. The administration of DCA for one week (5 mg. subcutaneously twice daily) failed to alter the blood pressure significantly of any of the normotensive group. In contrast, definite elevation of systolic and diastolic readings took place in one to four days in the hypertensive individuals, the mean systolic rise being $24 \mathrm{~mm}$. of mercury at the end of six days, the mean diastolic rise being $15 \mathrm{~mm}$.

Alterations in weight, hematocrit, serum volume and electrolytes, urine volume and chlorides were comparable in both groups. Ballistocardiographic tracings were unchanged in one hypertensive subject following a marked rise in blood pressure after DCA.

Although prolonged administration of DCA may give rise to a gradual increase in blood pressure in normotensive subjects, an accelerated response to DCA may be found in hypertensive vascular disease.

Measurement of Renal Blood Flow and Glomerular Filtration During Variations in Blood Pressure Related to Changes in Emotional State and Life Situation. JoHN B. Pfeiffer and Herbert S. Ripley, New York, N. Y. (Introduced by Harold G. Wolff).

Renal blood flow and glomerular filtration were ascertained by clearance measurements of para-aminohippuric acid and inulin respectively in ten human subjects with early hypertension. After a suitable control period in which subjects were reassured and made as comfortable as possible, topics of great significance in the life situation were abruptly brought up for discussion. In each instance the subject responded to the interview with a significant elevation of systolic and diastolic pressure but none gave evidence of fright or panic. Often their attitude was one of apparent calm and restraint during the period of elevated blood pressure. Evidence of renal arterial constriction was adduced in all cases during or after the interview. In four of the subjects a decrease of 20 percent or more in renal plasma flow occurred, one of these displaying also a significant decrease in glomerular filtration. In five of the subjects, despite elevation in systemic arterial pressure, no significant change in renal blood flow was found. In two of these an elevation of glomerular filtration occurred.

Subjects in whom lowering of blood pressure was induced by injection of tetraethylammonium chloride a significant increase in renal blood flow was noted. Similar lowering of blood pressure associated with increase in renal blood flow occurred when feelings of security were induced with the aid of sodium amytal.

\section{The Excretion and Reabsorption of Bicarbonate by the}

Normal Human Kidney. RoBerT F. PITTs, Syracuse, N. Y. (Introduced by James A. Shannon).

The renal excretion and reabsorption of bicarbonate was studied in three normal subjects over a range of plasma concentration from 18 to 39 millimols per liter. Plasma bicarbonate was reduced by the ingestion of ammonium chloride, raised by the intravenous infusion of sodium bi- 
carbonate. Blood was drawn from a cutaneous vein after heating the arm in water at $47^{\circ} \mathrm{C}$; ; both blood and urine were collected with precautions to prevent loss of carbon dioxide. The thiosulfate clearance was used as a measure of glomerular filtration rate. Carbon dioxide and $\mathrm{pH}$ measurements on plasma and urine permitted the calculation of bicarbonate contents and carbon dioxide partial pressures.

At plasma concentrations below 25 millimols per liter, the tubular reabsorption of bicarbonate was essentially complete. At plasma concentrations above 25 millimols per liter, the rate of excretion of bicarbonate progressively increased. There appears to be a limitation of the capacity of the tubules to reabsorb bicarbonate, the maximum quantity reabsorbed in the several subjects varying between 2.6 and 3.0 millimols per $100 \mathrm{cc}$. of glomerular filtrate.

The acidity of the urine varied between $\mathrm{pH} 4.48$ and

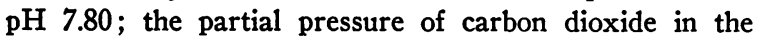
urine varied from about 30 to nearly $200 \mathrm{~mm}$. $\mathrm{Hg}$. The more alkaline the urine, the higher was the partial pressure of carbon dioxide.

Hypoelectrolytemia in Peritonitis. S. RAPOPORT and (by invitation) I. A. Syllm, N. Nelson, W. A. Brodsky and K. Dopd, Cincinnati, Ohio.

A decrease in the concentration of chloride and frequently of sodium has been described in tuberculosis, congestive heart failure, and in febrile diseases such as lobar pneumonia and typhoid fever.

In the present study, a lowering of the serum chloride and sodium, often accompanied by elevation of $\mathrm{CO}_{2}$ content and $\mathrm{pH}$, has been observed in children with peritonitis following rupture of the appendix. In some critically ill patients hypocalcemia was found. Clinically hyperpnea, a mild degree of edema, and decreased awareness of the surroundings were noted at the time of the appearance of the plasma changes. The disturbance of the electrolytes occurred within one or two days after the onset of the peritonitis and was self-limited in cases with a favorable outcome.

On an intake of 50-250 millimols of sodium chloride daily the urinary concentration of chloride and sodium was 20-60 millimols per liter; the hypoelectrolytemia persisted and retention of the sodium and chloride occurred.

The Pathogenesis of Hypercalcemia in Multiple Myeloma. Arnold J. Rawson, Philadelphia, Pa. (Introduced by F. William Sunderman).

The calcium partition was studied in sera obtained from normal individuals and from patients with multiple myeloma. In normal sera the average value of calcium bound to albumin was found to be 0.95 (s.e. $=0.045$ ) $\mathrm{mg}$. of calcium per gm. of albumin, and that of calcium bound to globulin, 0.74 (s.e. $=0.033$ ) $\mathrm{ml}$. of calcium per $\mathrm{gm}$. of globulin. In the sera of patients suffering from multiple myeloma the calcium binding property of albumin was increased to as much as six times the normal; the concentration of diffusible calcium and the calcium binding property of globulin in these sera remained within the normal range of values. Our studies indicate that when hypercalcemia is observed in patients with multiple myeloma, the increase is due to the calcium bound to protein. This increase in bound calcium is dependent upon two factors: (a) the increased calcium binding power of the serum albumin, and (b) the increased concentration of globulin, with approximately normal calcium binding property.

Renal Tubular Back-Diffusion Following Anuria. JULES Redish, Joseph R. West and Betty W. Whitehead (by invitation) and Herbert Chasis, New York, N. Y.

A negative value for $T_{m_{p a h}}$ was observed two and three and one half weeks following anuria in a patient with sulfathiazole intoxication. This negative $T_{m}$ indicates not only that the tubular cells had lost their ability to excrete PAH, but that a portion of the PAH filtered by the glomeruli was escaping from the tubular urine by backdiffusion.

Observations extending from two to ninety-two weeks from the onset of anuria showed a pattern of glomerular and tubular recovery. Glomerular filtration was markedly reduced for three weeks following the onset of anuria and then returned abruptly to the normal range. Tubular excretory capacity was impaired for some weeks thereafter.

The data show the limitations of clearance measurements of flitration rate, renal blood flow and maximal tubular excretory capacity in the diseased kidney; and they suggest that a common mechanism, renal vasoconstriction with ischemia, may operate to produce glomerular and tubular changes during and after a period of anuria, whether the anuria is associated with diffuse glomerulonephritis, post-transfusion reaction, sulfathiazole intoxication, crush syndrome, shock or ureteral trauma.

Clinical and Experimental Observations on the Lability and Range of Blood Pressure in Essential Hypertension, with Special Reference to Physiologic Mechanisms and Significance of Various Pressor and Depressor Tests. Morton F. ReIser (by invitation) and Eugene B. Ferris, Cincinnati, Ohio.

Important in selecting the type of therapy for the patient with essential hypertension is a careful evaluation of the "neurogenic factor." As part of a comprehensive clinical, physiologic, and psychiatric study of essential hypertension, data pertinent to this problem has emerged. Comparative results in 107 pressor and depressor tests (1) performed on twenty-three patients indicate that extreme caution must attend their interpretation in the individual case.

Variations of blood pressure in response to emotional or environmental stimuli may equal or exceed those elicited by the usual pressor and depressor tests. The patient's response to different tests, or the same test repeated, may vary considerably, and there may be significant response to only a few of many procedures. There is no constant correlation between degree of reactivity to pressor tests and clinical lability.

In four patients with malignant hypertension, reductions in pressure to or very near normal occurred, three in re- 
sponse to sympathetic block, one spontaneously. This together with other data (2) to be presented suggests that neurogenic factors play a significant contributing role even in this stage.

Preliminary studies utilizing the differential effects on blood pressure and cold pressor test of procedures which block neurogenic responses in different portions of the arteriolar bed have been helpful in leading toward a better understanding of the basic physiologic mechanisms involved and in explaining some of the apparent incongruities (3) of results which make selection of patients for sympathectomy so difficult.

(1) Test procedures used singly or in various combinations include: cold pressor; breath holding; postural changes; provocative interviewing; ammonia inhalation; hyperventilation plus carotid sinus massage; environmental manipulation; caudal, spinal, pentothal and gas-oxygenether anesthesia; and parenteral administration of the tetraethylammonium ion.

(2) In four instances we have observed the development of malignant hypertension and hypertensive encephalopathy in direct response to known environmental situations which, when appraised in the light of the psychiatric history, had specific psychological meaning for the patients.

(3) E.G., in some patients who exhibit spontaneous downward variations in blood pressure to normal levels, spinal or caudal anesthesia may fail to produce such a satisfactory fall in pressure. When, in this circumstance, the tetraethylammonium ion, which effects a total autonomic block, is able to reproduce the fall to normal it seems probable that extra splanchnic arteriolar resistance may be playing an important role.

\section{A Specific Cutaneous Test for the Immune Response to} Herpetic Infection. HARRY M. RoSE and (by invitation) Eleanora Molloy, New York, N. Y.

Chick embryos inoculated by the yolk sac route with the virus of herpes simplex develop a high titer of virus in the chorioallantoic fluid. Antigens for cutaneous testing were prepared from this infected, undiluted fluid by inactivating the virus at $56^{\circ} \mathrm{C}$. Such antigens contain little egg protein and provoke a minimal number of nonspecific dermal reactions.

Cutaneous tests were performed on 44 patients with herpes antigens and with control antigens prepared from normal chorioallantoic fluid. The blood of each patient was examined for neutralizing antibody to herpes virus by the method of chorioallantoic membrane inoculation with serum-virus mixtures.

Twenty-nine patients whose sera contained antibody gave positive cutaneous tests with herpes antigen and negative tests with control antigen. Thirteen patients, mostly children, whose sera were devoid of antibody gave negative cutaneous tests with both antigens. In one patient the cutaneous tests were negative although the serum contained antibody. In another patient the tests could not be interpreted because of marked sensitivity to egg protein.

There appears to be a high degree of correlation between positive cutaneous reactions to herpes antigens, as herein described, and the presence of circulating antibody to herpes virus.

Recognition of Metastatic Neoplasm in Bone Marrow. R. W. Rundles, Durham, N. C. (Introduced by D. T. Smith).

Invasion of the bone marrow by neoplasm may produce refractory anemias, sometimes with immature granulocytes or nucleated red blood cells in the circulating blood, hemolytic anemias, thrombopenic purpura, as well as diffuse bone pain, destructive skeletal lesions, etc. Diagnosis may be extremely difficult when the primary tumor escapes recognition or if involved tissue is not accessible for biopsy.

The possibility of recognizing tumor implants in bone marrow was studied in 40 patients having malignancies with local spread or distant metastases. Marrow was obtained from the ribs or sternum by combined aspiration and needle trephine preferably in areas of increased bone tenderness. Spread films were stained by Wright's stain A positive diagnosis of metastatic neoplasm was made in 14 cases. The malignant cells occurred singly, in sheets, and in clumps among other bone marrow elements. The presence of neoplasm in the marrow was confirmed by sections of tissue obtained by trephine, biopsy and necropsy.

Neoplastic implants in the bone marrow were found in patients before definite roentgen, peripheral blood, or blood chemical abnormalities appeared. Serial biopsies were readily obtained and were used to follow the response of prostatic metastases to orchidectomy and estrogenic therapy, the response of breast cancer to androgenic hormones, and other malignancies treated with nitrogen mustard compounds or radiation therapy.

Pitressin Test of Coronary Insufficiency. ARTHUR RUSKIN, Galveston, Texas (Introduced by George M. Decherd).

Pitressin, a well-known experimental coronary vasoconstrictor, was used in human subjects both intramuscularly ( 2 cc. or 40 pressor units) and intravenously $(0.75 \mathrm{cc}$. in subjects of average weight) for the electrocardiographic demonstration of coronary insufficiency. The not infrequent untoward symptoms-nausea, vomiting, abdominal discomfort-were easily controlled. In normal individuals EKG changes were limited to bradycardia, ectopic beats and slight S-T segment depressions.

In cases of definite clinical angina pectoris positive tests were found in 8 of 12 cases. The number of positive Master two-step tests in these 12 patients was 7. Our electrocardiographic criteria of coronary insufficiency were fairly rigid: S-T depressions totalling 3 $\mathrm{mm}$. or more in the 4 commonly used leads, or $T_{1}, T_{2}$, or $T_{3}$ changes from positive to flat, diphasic or negative $T$ waves. All 10 cases of suspected pseudo-angina, with indefinite clinical features, had negative pitressin and Master tests. Patients with abnormal EKG's prior to the test were found to be subject to the same criteria in both groups as were those with normal control tracings. 
In view of the close parallelism between the effects of exercise and pitressin in individuals with and without clinical angina pectoris, pitressin may be used by cardiologists to confirm the clinical suspicion of coronary pain. The above results form a further link in the evidence for both coronary spasm and relative myocardial ischemia as theoretical bases for clinical anginal pain.

\section{Microchemical Studies of Human Urinary Estrogens. W. T. Salter and (by invitation) M. Jane Oester- LING, New Haven, Conn.}

Studies of estrogen excretion in various types of patient and normal controls have been conducted on 6-hour to 12-hour samples of urine. The normal adult human male excretes only about 10 micrograms of estrogenic substances daily. Near menstruation, some women approach closely the male value. In the intermenstruum, however, female values rise steadily toward the time of ovulation. At this crisis, the peak of excretion temporarily may reach 90 micrograms. In certain sterile women, the male level may prevail continuously. In other sterile women, the estrogen level may be normal, but overshadowed by high "androgens." Therefore it is useful to know the ratio of antithetical steroids (estrogens vs. 17-ketosteroids) in the identical 6-hour sample of urine, as well as the absolute levels of either. The "antithetical ratio" of normal males is usually less than 1.0. In normal females, it is usually above 2.0 and at ovulation may reach 9 . In female adrenal virilism and in Cushing's syndrome the ratio is usually in the male range. In female pseudohermaphroditism, however, the high "androgen" excretion may be balanced by a high estrogen value. In prostatic disease, high ratios are found. Thus studies of steroid balance may be useful in precise diagnosis.

Nitrogen Metabolism and Nutritional Studies in Chronically Ill (Metabolically "Debilitated"), Undernourished Patients. Victor Schenker and L. G. Johnson (by invitation), and J. S. L. Browne, Montreal, Canada.

The nitrogen metabolism, nutrition, and clinical course have been followed in a series of hospital patients with various chronic diseases (pulmonary tuberculosis, rheumatoid arthritis, bronchiectasis, peptic ulcer), and with varying degrees of weight loss. Representative experimental results are presented.

All subjects were placed on controlled dietary regimes over certain periods of time. Experimental diets varied as to total content of protein and calories (Prot. 100-200 gm./ day; Cals. 2,500-3,500/ day).

On these food intakes all subjects gained weight; the majority showed general improvement clinically with increased strength and feeling of well-being.

All showed abnormally low rate of urinary nitrogen excretion (with a consequent high nitrogen retentionunattributable to raised blood N.P.N.), which has been shown to characterize the metabolically "debilitated" individual. In many instances, however, nitrogen retention continued at the same rate even after considerable amounts had been stored over prolonged periods of time, and increase in body weight ceased. Further, in a num- ber of cases, the total nitrogen retained, calculated as "tissue-protein," was found to be greatly in excess of the actual total gain in weight. Factors which may be responsible for these anomalies are discussed.

Radioiodine Excretion in the Gastric Juice and Saliva of Man. Leon SchIfF and (by invitation) CharLes D. Stevens, Harold H. Steinberg, Carl W. Kumpe and Paul Stewart, Cincinnati, Ohio.

The excretion of radioiodine in the gastric juice and in the saliva of 35 individuals was followed at ten-minute intervals for two hours after the intravenous administration of $0.01 \mathrm{mM}$ (1.5 mg.) of $\mathrm{NaI}$ and 4 microcuries of radioiodine per $\mathrm{kgm}$. of body weight. Plasma levels of 0.04 to $0.08 \mathrm{mM}$ of iodine per liter 15 minutes after the injection declined to 0.01 to $0.02 m M$ by $1 \frac{11}{2}$ hours after injection.

The concentration of radioiodine in gastric juice following the injection . usually rose to 20 to 40 times the plasma concentration. The concentration in the saliva also rose to similar levels, frequently exceeding the concentration in the gastric juice.

The concentration of radioiodine in both the gastric juice and the saliva showed great variability from individual to individual, as well as upon repeated tests on a single individual. The variability in radioiodine excretion in the gastric juice was not related to the $\mathrm{pH}$ of the juice, nor to its volume, nor to the amount of visible mucus in it.

No definite relation has been observed between any gastric disorders and the excretion of radioiodine in the gastric juice.

The Metabolism of Americium (Element 95) in the Rat.* K. Scott, D. Axelrod, and H. Copp (by invitation), and J. G. Hamilton, Berkeley, Calif.

Solutions of $\mathrm{Am}\left(\mathrm{NO}_{3}\right)_{3}$ were administered to 200-gram rats by intramuscular injection and by stomach tube. The stomach tube series were sacrificed at 4 days, and the animals which received the americium by intramuscular injection were sacrificed at 1, 4, 16, 64, and 256 days. The absorption from the digestive tract was too small to be detected, indicating that less than 0.01 per cent of the administered dose was absorbed. The americium that was absorbed following intramuscular injection was accumulated primarily in the liver and skeleton. The initial accumulation in the liver represented nearly 65 per cent of the total amount absorbed from the site of intramuscular injection. The corresponding value of americium deposition in the skeleton was approximately 25 per cent. Within 16 days over two-thirds of the americium had left the liver and by 64 days less than 5 per cent remained in that organ. The content of americium in the skeleton remained constant up to and including the 256 day interval; evidently it becomes extremely firmly fixed in bone. Excretion was chiefly by way of the digestive tract and was roughly equivalent to the rate and degree of loss from the liver. Radio-auto-

* This work was performed under Contract W-No. 7405-eng-48-A for The Manhattan Project. 
graphic studies of undecalcified bone sections indicated that americium accumulates chiefly in the region of the endosteum, periosteum, and trabecular bone. The metabolic behavior of this new element resembles most closely the distribution in the animal body of the lanthanide rare earths, notably lanthanum, cerium, and praseodymium.

Biochemical Changes in Hypertension. Frances Selye, Montreal, Canada (Introduced by J. C. Meakins).

Recent investigations have suggested that the adrenal cortex, through its influence on electrolyte metabolism, may play a role in the pathogenesis of hypertension. Clinical improvement reported on low salt diets has appeared to confirm this. Investigating this problem clinically we have noted in hypertensive patients an increase of blood $\mathrm{Na}$ relative to blood $\mathrm{Cl}$ present almost without exception in patients whose sustained, average diastolic pressure was greater than 116 (average of diastolic in our series). Among those with increased ratios, most fell into an age group under 50 years. There was also a tendency for $\mathrm{CO}_{2}$ combining power to increase with increasing diastolic pressures.

We feel these changes to be analagous to the hypochloremic alkalosis of Cushing's disease and that they probably indicate an "active" or ascendant phase of the disease. In general there has been little overlap between cases showing this biochemical pattern and cases judged appropriate for sympathectomy.

Twenty-five per cent of our cases under 50 years of age give a clear-cut history of previous rheumatic fever or rheumatoid arthritis, indicating a probable connection between these so-called "diseases of adaptation."

Results of therapy with ammonium chloride have been encouraging in those cases showing biochemical abnormalities, while there are few favorable responses among the others.

The Virus of Encephalomyocarditis and Its Apparent Causation of Disease in Man. JoSEPH E. SMADEL and (by invitation) JoEL W ARREN, Washington, D. C.

The virus of encephalomyocarditis (E.M.C.), recently isolated from a chimpanzee in Florida, is apparently a hitherto undescribed agent which induces lesions in the brain and myocardium of infected rodents and monkeys. Convalescent animals develop specific neutralizing antibody.

Neutralization tests performed in mice with this agent and the sera from 31 persons recently recovered from rheumatic fever, idiopathic myocarditis, encephalitis, or aseptic meningitis gave negative or inconclusive results. None of 29 normal persons had these antibodies.

During the winter of 1946, numerous cases of "Three Day Fever" occurred among Army personnel stationed in and near Manila, P. I. Materials were received for study from 44 soldiers with this disease which is characterized by chills, fever and severe headache, and usually a stiff neck and pleocytosis (50-500 cells). Sera from 17 of the 44 patients had appreciable amounts of specific neutralizing antibody for the E.M.C. virus. Rising antibody titers were demonstrated in three of the four patients from whom several samples were available.
Sera containing E.M.C. antibodies failed to neutralize Japanese encephalitis virus or fix complement with lymphocytic choriomeningitis or mumps antigen. E.M.C. antibodies were not detected in sera of soldiers with a similar epidemic disease occurring in several other oriental areas.

Production of Acute Experimental Heart Failure in Dogs with Intact Circulation. JoHN R. SMITH and Albert Roos, St. Louis, Mo. (Introduced by Henry A. Schroeder).

The mechanisms leading to congestive heart failure are not clearly understood. Experience with the heartlung preparation indicates that heart failure occurs when the myocardium is sufficiently damaged, other work factors remaining unaltered.

Accumulating experimental evidence suggests that elevation of the circulating or "effective" blood volume, from various causes, is concerned in initiating congestive failure. Report is made of five dogs, anesthetized, with circulations intact, in which the hearts were damaged by coronary ligations or by widespread coronary embolization with potato starch emulsion. These animals either suffered lethal shock or died suddenly of ventricular fibrillation. No evidence of cardiac failure was noted. However, seven animals were first transfused with blood, to produce a significant elevation of arterial blood pressure. Cardiac damage was then inflicted in the same way. Acute congestive heart failure resulted (showing elevated venous tension, dilatation of the heart and other pathognomonic signs). This evidence appears to warrant the suggestion that the damaged myocardium may be precipitated into failure when the "effective" blood volume is elevated to impose sufficient cardiac work. It is further suggested that the increased blood volume tends to nullify the effects of peripheral vasodilatation which may otherwise spare the damaged heart.

\section{The Effect of Iodine and Adrenalin Administration on Circulating Thyrotropic Factor. Lours J. SoFFER and (by invitation) Mario Volterra, Lester Gabrilove, Abou Pollack and Mildred Jacobs, New York, N. Y.}

The following report deals with experimental investigations on: 1 . The relationship between the anterior hypophysis and the thyroid gland and the mechanism of iodine action; and 2. The possible role of adrenal activity on promoting thyrotropic discharge. Bioassay of serum of hyperthyroid patients before and during lugolization reveals increased thyrotropic content of the serum during treatment with iodine, as shown in the thyroids of young guinea pigs. The effect is of short duration and not always of the same intensity. This suggests that iodine prevents the access of thyrotropic factor to the thyroid.

We have found that prolonged administration of adrenalin (in oil) in the dog is followed by hyperplastic changes in the thyroid. The histological picture is that of colloid resorption, epithelial hyperplasia, and sometimes disappearance of the alveolar structure and substitution of it with homogenous adenomatous tissue. These changes are patchy in character but involve large areas. Bioassay of the serum of thyroidectomized dogs after adrenalin ad- 
ministration shows increased circulating thyrotropic hormone as demonstrated by hyperplastic changes in the thyroid of guinea pigs.

It is remarkable that the demonstration of increased thyrotropic activity due to the effect of adrenalin parallels recent reports of Long concerning increased corticotropic activity following adrenalin.

An improved histological technique, recently suggested by Dr. Robertis and by Dempsey, is now being applied for a finer evaluation of these results.

Coexisting Addison's Disease and Diabetes Mellitus: Comparative Effects of Compound E (17-Hydroxy-11Dehydrocorticosterone) and Allied Substances in Three Cases. Randall G. Sprague and Edwin J. Kepler (by invitation), F. RAYMond Keating, JR., and (by invitation) Marschelle H. Power, Rochester, Minn.

Response to the administration of compound $\mathrm{E}$ and allied substances was studied in three patients having both Addison's disease and diabetes mellitus. Observations were made during periods of fasting while the "salt and water" deficiency of Addison's disease was being controled with 11-desoxycorticosterone acetate or sodium chloride or both. The first patient, a man who had both diseases in relatively mild form, was able to fast without decline of the level of blood sugar while receiving compound $E$. The other two patients were women with severe Addison's disease and fundamentally severe diabetes. When they fasted following withdrawal of insulin during treatment with compound $\mathrm{E}$, severe ketosis developed and relatively large amounts of sugar and nitrogen were excreted in the urine. In one of the latter two patients, 8 c.c. of hog adrenal extract (lipo-adrenal cortex) daily had slightly less effect than $8 \mathrm{mg}$. of compound $\mathrm{E}$ daily.

Other substances studied in this fashion had less effect than compound $\mathrm{E}$ on the metabolism of carbohydrate. In none of the three patients did 11-desoxycorticosterone acetate exhibit significant carbohydrate activity. Except in one patient, compound A (11-dehydrocorticosterone) showed little carbohydrate activity.

The results demonstrate that in the human being, as in animals, compound $E$ has a much greater effect on carbohydrate metabolism than 11-desoxycorticosterone acetate or compound $\mathrm{A}$.

The Relation of Protein-Binding to the Pharmacology and Antibacterial Activity of Penicillins $X, G$, Dihydro $F$ and $K$. Ralph Tompsett and Selma Shultz, New York, N. Y. (Introduced by Claude E. Forkner).

A study has been made of the effects of whole serum and purified plasma fractions on the action of the four crystalline penicillins-p-hydroxybenzylpenicillin (X), benzylpenicillin (G), n-amylpenicillin (dihydro $F$ ) and $n$ heptylpenicillin $(\mathrm{K})$.

It has been observed that the antibacterial activities of these four penicillins are antagonized to different degrees by whole serum and also by the albumin fraction of serum in vitro.

The degrees of antagonism parallel the known antibacterial activities of these penicillins in vitro, as determined in the absence of serum. Penicillin X, which has the lowest potency in units per milligram, is antagonized the least, and penicillin $\mathrm{K}$ which has the highest potency, is antagonized to a much greater degree.

The degrees of antagonism of these four penicillins by serum are roughly in direct proportion to their degrees of binding to serum and to the albumin fraction of serum in vitro, as determined by dialysis experiments. The average degree of binding to serum varies from 47 per cent of $\mathrm{X}$ to 91 per cent of $\mathrm{K}$.

Evidence has been obtained which indicates that the phenomenon of protein binding during the bioassay procedure affects the measurement of all of these penicillins in specimens of serum. The effect so produced materially alters previous interpretations of the rates of disappearance of these penicillins from the circulating blood of man, particularly in regard to penicillin $\mathrm{K}$. Comparative studies of these rates of disappearance, in which the factor of protein binding was controlled, have been made. The results of these studies indicate that the rate of fall in serum concentration of penicillin $\mathrm{K}$ is less rapid than that of the other three penicillins.

The data indicate that there is an inverse relationship between the degree of binding of the individual penicillins in vitro and their effectiveness in vivo in the treatment of infections in experimental animals.

Parasitization of Mouse Sarcoma 180 by Vaccine Virus and its Effect on Tumor Growth. JOSEPH C. TURNER and (by invitation) Barbara Mulliken, New York, N. $Y$.

An investigation into the possibility that propagation of a virus in a neoplasm might result in retardation of tumor growth has been begun with vaccinia and mouse sarcoma 180.

Calf-lymph virus was adapted to mouse brain. Injected as $0.1 \mathrm{ml}$. of brain suspension in vivo into established tumor grafts, the virus, even after inactivation at $56^{\circ}$ for 2 hours, proliferated and was readily recovered from the tumors a few days later. These virus-infected tumors were grossly and microscopically indistinguishable from control sarcomas.

Grafted into 36 normal young mice fragments of virusinfected tumors grew less successfully than 36 control transplants. Palpable nodules were relatively slow both to become appreciable and to increase in size. One week after all control grafts had by their crippling bulk necessitated sacrifice of their hosts, at least 20 per cent of the virus-infected grafts had shown no sign of growth and at autopsy could not be discovered. The majority of the tumors than had by this time become established were smaller than comparable controls and contained virus. During the period of observation the animals gained and maintained weight.

In another strain of mice similar findings have been encountered.

Analysis of the effect is incomplete. It seems not likely to be an expression of variability of sarcoma 180 or of ill-health of the hosts, and might represent a selective restrictive action on tumor by the parasitizing virus. 
Zn Metabolism Studied by Means of the Radioactive Isotope ${ }_{0} Z n^{\circ 5}$. Bert L. VALLEE and REX G. FluharITY, Boston, Mass. (Introduced by John G. Gibson, 2nd).

External scanning with a gamma ray Geiger-Müller counter has shown that, following i.v. administration, ${ }_{30} \mathrm{Zn}^{\text {es }}$ becomes widely distributed throughout the entire body of the normal dog. The normal range of zinc content of organs has been determined in normal dogs by an improved dithizone method. The ranges, in completely perfused organs, in gamma per gram (wet weight), are: heart and great vessels 15-20; respiratory organs 10-20; digestive organs $10-60$; genito-urinary tract $20-50$; muscle 40-50; cortical bone 40-50; C.N.S. (brain) 10-15; endocrines $20-100$; lymph glands $15-100$; liver $50-60$; spleen 10-20; marrow 60-80; plasma 2-4 (per cc.) ; whole blood 7-9. Simultaneous measurements of $\mathrm{Zn}^{\text {es }}$ and total zinc content have not shown selective localization of the element in any of the above organs.

The complete separation of white cells from blood can be effected by floatation of heparinized whole blood on an isosmotic solution of bovine serum albumin of specific gravity of approximately 1.079 . The normal zinc content of white cells is $1 \times 10^{-2}$ gamma and of red cells $1 \times$ $10^{-4}$ gamma per million cells, respectively. Following the intravenous injection of $\mathrm{Zn}^{\text {es }}$ the isotope becomes concentrated within the circulating white cells in amounts sufficient for accurate $x$-ray detection in the leucocyte mass separated from $15 \mathrm{cc}$. of whole blood (1.0 to $2.0 \times$ $10^{8}$ w.b.c.).

Blood, white cells and tissue samples are dry ashed, and the zinc extracted with dithizone for colorimetry. The zinc is removed from the dithizonate with sulfuric acid and electroplated from an alkaline solution with added carrier zinc on a copper disk. The $x$-ray counting procedures are similar to those used to measure $\mathrm{Fe}^{\mathrm{ss}}$.

These procedures have opened the way to a study of overall zinc metabolism in addition to the physiology of leucocytes.

Late Manifestations of Epidemic Infectious Hepatitis. Wade Volwiler and Joseph A. Elliot Boston, Mass. (Introduced by Chester M. Jones).

Accurate and complete observations on the late manifestations of epidemic infectious hepatitis are relatively rare. Needle liver biopsy and multiple laboratory tests were carried out on twelve army and civilian patients having symptoms of this disease four months to twentyone years after the initial illness. A small group with continued mild jaundice showed normal liver histology and normal liver function tests with no evidence of a hemolytic process. Of the remaining eight, all showed definite histologic evidence of a persisting inflammatory process associated with clinical symptoms of varying severity. Abnormal physical signs and symptoms did not correlate well with the degree of observed histologic damage. Bromsulfalein excretion was the only consistently abnormal hepatic function test in this group. The sedimentation rate was usually elevated, in contrast to the normal values commonly seen in the acute phase of the disease. Flocculation tests and quantitative 24-hour urine urobilinogen determinations frequently did not re- flect the histologic abnormalities. Two patients with severe laboratory hepatic functional impairment were found to have developed fibrosis in association with still active inflammation. Colored photomicrographs of biopsy specimens will be shown.

The Hemodynamics of Rapid Changes in Cardiac Output in Man. James V. Warren, New Haven, Conn., and (by invitation) EMMETT S. BranNoN and Frederick W. COOPER, JR., Atlanta, Ga.

Patients with large arteriovenous fistulas offer an unusual opportunity to study the hemodynamic alterations associated with rapid changes in cardiac output. Ballistocardiographic studies on fifty such patients during the recent war indicated that the resting cardiac output was often abnormally high, and on occlusion of the fistula fell to a normal value. Further observations on the nature of these circulatory alterations have been made in 14 patients utilizing the technique of right heart catheterization.

The present observations confirmed the ballistocardiographic findings. In the patients with a large stroke volume, the arteriovenous oxygen difference (determined from right heart blood) was found to be low, with blood draining the area of the fistula giving evidence of an even lower arteriovenous oxygen difference.

Although the venous pressure near the fistula and distal to it was elevated in some instances, the right atrial pressure was normal in all patients where it was studied. Although compression of the fistula produced a striking fall in cardiac output in some patients, there was no change in atrial pressure. Experimental lowering of the atrial pressure failed to produce significant change in cardiac output, thus indicating that minor undetectable changes in atrial pressure were not responsible for the changes in cardiac output.

The right ventricular and pulmonary arterial pressure were recorded in four patients during opening and closing of the fistula. Despite considerable change in cardiac output, only minimal change in pressure and pulse contour occurred.

These observations give further support to the belief that wide variations in cardiac output may occur in the absence of significant change in atrial pressure. The constancy of pulmonary arterial pressure indicates a rapid, presumably reflex, alteration in pulmonary vascular resistance associated with changes in cardiac output.

Kidney Function Studies in Adrenal Insufficiency. Christine Waterhouse and E. Henry Keutmann, Rochester, N. Y. (introduced by William S. McCann).

The glomerular filtration rate (mannitol), renal plasma flow (PAH), and maximum tubular excretory capacity (PAH) were studied in six male and six female patients with adrenal insufficiency. Nine had Addison's Disease and three had pan-hypo-pituitarism. All were in good clinical condition at the time of study.

All female patients had markedly reduced maximum tubular excretory capacity. This function was normal in all males except two patients who had hypertension. These results suggest that maintenance of approximately 
normal amounts of functioning tubular tissue occurs only in males.

The reduced tubular function in females was not corrected by desoxycorticosterone acetate, testosterone propionate, thyroid, aqueous adrenal cortex extract in large doses or pork adrenal cortex extract in oil.

The renal plasma flow was normal in two men but in all other patients it was below normal. Neither clinical nor laboratory data clarified this difference entirely but the patients with Addison's Disease receiving desoxycorticosterone acetate had a greater decrease of renal plasma flow than reduction in the ability of the tubules to excrete PAH (low ratio R.P.F/Tm). This suggests that the post glomerular arterioles are constricted by the hormone.

All patients had reduced glomerular filtration rates at all times. While this defect may be exaggerated in crisis and improvement is caused with restoration of electrolyte deficit by administration of salt, adrenal cortex extract or desoxycorticosțerone, normal values are not attained.

Correlation between the Effect of Quinidine Sulfate on the Rate of the Circus Movement in Auricular Fibrillation and its Concentration in the Blood Plasma. RENE WEGRIA, New York, N. Y. (Introduced by Alexander B. Gutman).

Patients with auricular fibrillation were given orally single and repeated doses of quinidine sulfate. The concentration of the drug in the plasma and the intensity of its effect on the rate of the circus were followed.

In 7 studies in which one single dose $(0.4 \mathrm{gm}$. to 0.8 gm.) of quinidine was given, the intensity of the cardiac effect of the drug and its plasma concentration were found to be grossly parallel but not parallel in a strictly quantitative manner. Indeed, discrepancies between intensity of cardiac effect and plasma concentration were found, the plasma level of the drug decreasing faster than the intensity of its cardiac effect. In 3 studies in which repeated doses ( $0.4 \mathrm{gm}$. every 2 hours for 3 or 4 doses) were given, there was a less marked discrepancy between plasma concentration and intensity of cardiac effect. Several possible explanations which may account for the discrepancies between the plasma level of the drug and the intensity of its cardiac effect, were investigated.

Observations on a Perfusion Method for Reducing Azotaemia in Temporary Renal Failure. Donald M. Whitlaw, Toronto, Canada (Introduced by W. Hurst Brown).

Perfusion of the peritoneum was carried out for six days in a patient with extreme oliguria of five days duration due to sulfathiazole nephrosis. Perfusion fluid was solution "A" of Abbott and Shea with added heparin, penicillin and streptomycin. Perfusion rate was 1.5 liters per hour for two days and 0.4 liters an hour for the four subsequent days. Nonprotein nitrogen was reduced from $145 \mathrm{mg}$ per cent to $82 \mathrm{mg}$ per cent in the first two days and maintained at that level. Carbon dioxide combining power was maintained between 18 and $21 \mathrm{mEq}$. per liter. Edema was at first reduced but later reappeared due to loss of protein in the perfusate. A total of 71.35 liters of perfusate was recovered which contained $46.4 \mathrm{gm}$. of nonprotein nitrogen and $178 \mathrm{gm}$. of protein. Concentration of nonprotein nitrogen in the perfusate averaged $70 \mathrm{mg}$. per cent and varied directly with the length of time that the fluid remained in the peritoneal cavity. Diuresis began on the second day of perfusion and reached 5.5 liters on the last day. Twenty-five days later urine output was normal. Urinary specific gravity remained fixed between 1.010 and 1.012. Urea clearance was 25 cc., nonprotein nitrogen was $42 \mathrm{mg}$ per cent. No peritoneal infection occurred.

\section{The Effects of Splanchnicectomy upon Hepatic Function} and Blood Flow in Hypertensive Patients. ROBERT W. Wilkins, (by invitation) James W. Culbertson and Franz J. Ingelfinger, Boston, Mass.

Hepatic function and blood flow were estimated in hypertensive patients before, and again early after sympathectomy (Smithwick) by the method of Bradley et al. Briefly this involves the measurement of BSP concentration in serial pairs of samples of peripheral and hepatic (catheter method) venous blood, during a constant intravenous infusion of the dye. In the presence of a constant, or constantly changing, peripheral blood level of BSP calculations of total removal rate may be made. The hepatic extraction of BSP is represented by the peripheral-hepatic venous difference. Hepatic blood flow is estimated by dividing the total removal rate by the extraction.

Preoperative values for total BSP removal rate and estimated hepatic blood flow fell within the normal range. Postoperative measurements revealed a marked decrease in total removal rate of BSP, usually associated with a marked decrease in hepatic extraction. The data indicated that hepatic blood flow was markedly increased when resting blood pressure was unchanged after splanchnicectomy, whereas it was increased only slightly or not at all when blood pressure was lowered. These results suggest that sympathectomy markedly decreases the resistance to blood flow through sizable portions of the splanchnic beds draining through the liver.

The cause of the decrease in total BSP removal rate after sympathectomy is not clear, but probably is not a non-specific postoperative debility, since no decrease occurred after other major surgical procedures. Perhaps it is related to the increase in hepatic blood flow.

How Should Thyrotoxicosis Be Treated? ROBERT $H$ Williams and (by invitation) Samuel P. Asper, Jr., Walter F. Rogers, Jr., William H. Daughaday and Beverly T. Towery, Boston, Mass.

The increased availability of many effective and relatively safe antithyroid drugs and of radioactive iodine has made it necessary, in choosing the best treatment in thyrotoxicosis, to give individual consideration to the problems of each patient. As a result of treating 320 thyrotoxic patients with from 1 to 16 thiourea or aminobenzene derivatives, of following 28 individuals treated with radioactive iodine, of observing 155 patients subjected to thyroidectomy, and on the basis of the experiences reported by others, it has been possible to draw 
tentative conclusions regarding the choice of therapy in this disease.

The antithyroid drugs are desirable in a large proportion of individuals because of the simplicity of administration, availability, inexpensiveness, regulability, safety, relative lack of physical or mental discomfort, and lack of damage to the thyroid gland and surrounding structures. The compounds tested clinically in this clinic are: tetramethylthiourea, diethylthiourea, thiourea, 2-thiobenzimiazoldine, aminothiazol, thiothymine, thiobarbital, thiouracil and 6-methyl-, 6-propyl-, 6-cyclopropyl-, 6butyl-, 6-isobutyl-, thiouracil. p-Aminobenzoic acid and its 3,5-diiodo derivative, as well as 3,5-diiodo-o-aminobenzoic acid have also been used. Of these compounds, 6-propyl-, 6-cyclopropyl-, and 6-butyl- thiouracil are the ones of choice. They have a high degree of effectiveness and the complications from their use are very infrequent. The pharmacology of the derivatives of thiouracil was found to be similar to that of thiouracil, but they tend to be broken down more slowly and are concentrated more in the thyroid gland, in rats. Substituents in the 6-position of thiouracil bearing an odd number of carbon atoms (methyl, propyl and amyl derivatives) persist in the carcass in greater concentration and in the thyroid gland in less concentration than was found with ones containing an even number of carbon atoms (ethyl and butyl). The antithyroid activity of thiouracil and propylthiouracil is enhanced by the simultaneous administration of bromide, fluoride and chloride, presumably due to competitive reactions of these halides with iodine.

Radioactive iodine is quite useful in thyrotoxic patients who have large goiters, individuals who cannot or will not take prolonged therapy, and ones who have not responded satisfactorily to antithyroid drugs or to thyroidectomy. It is also useful in certain patients with carcinoma of the thyroid gland which has metastasized.
It is not necessary for a large proportion of patients to be subjected to thyroidectomy, but this procedure is desirable in certain individuals with a large thyroid gland, in ones who may likely have carcinoma of the thyroid and in the small number of subjects who cannot be satisfactorily treated otherwise.

\section{Sustained Contraction of the Diaphragm, the Mechanism of a Common Type of Dyspnea and Precordial Pain. Stewart Wolf, New York, N. Y.}

Complaints of respiratory distress characterized by inability to get a full breath were found to occur commonly among anxious individuals and among those who did not obviously display anxiety. By discussion of. situational conflicts, attacks were induced in 17 subjects during flouroscopic observation. In each instance a characteristic disorder of diaphragmatic function was observed. Inspiration became jerky and the excursion of the diaphragm exceeded that in expiration. The diaphragm thus assumed a progressively lower position. When its contractile state was such that an adequate inspiratory excursion was no longer possible, dyspnea occurred with a feeling of inability to take a breath. Frequently pain in the precordium, elsewhere in the chest, and in the shoulder accompanied such sustained diaphragmatic contraction.

Three subjects had attacks accompanied by pallor, sweating, fall in blood pressure and angor animi, simulating superficially the syndrome of coronary occlusion.

In seven of the subjects occlusion of the cardiac end of the esophagus during diaphragmatic spasm was demonstrated with barium. Occasionally esophageal occlusion occurred when the increase in contractile state of the diaphragm was insufficient to impair ventilation of the lungs and cause dyspnea. Such patients also complained of difficulty in swallowing. 